\title{
Mechanisms for Diurnal Variability of Global Tropical Rainfall Observed from TRMM
}

\author{
Song Yang ${ }^{1}$ and Eric A. Smith ${ }^{2}$ \\ ${ }^{1}$ School of Computational Sciences, George Mason Univ., Fairfax, VA 22030 \\ [Mail Code 912.1, NASA/Goddard Space Flight Center, Greenbelt, MD 20771 \\ (301) 286-4961; <ysong@agnes.gsfc.nasa.gov> \\ 2 NASA/Goddard Space Flight Center, GPM Project Science/Code 912.1, Greenbelt, MD 20771 \\ (301) 286-5770; <eric.a.smith@nasa.gov>
}

August 2004

Submitted to

Journal of Climate

Corresponding Author

Dr. Eric A. Smith

GPM Project Science / Code 912.1

NASA/Goddard Space Flight Center

Greenbelt, MD 20771

(301) 286-5770

<eric.a.smith@nasa.gov> 


\section{Abstract}

The behavior and various controls of diurnal variability in tropical-subtropical rainfall are investigated using Tropical Rainfall Measuring Mission (TRMM) precipitation measurements retrieved from: (1) TRMM Microwave Imager (TMI), (2) Precipitation Radar (PR), and (3) TMI/PR Combined -- standard level 2 algorithms for the 1998 annual cycle. Results show that the diurnal variability characteristics of precipitation are consistent for all three algorithms, providing assurance that TRMM retrievals are providing consistent estimates of rainfall variability. As anticipated, most ocean areas exhibit more rainfall at night, while over most land areas rainfall peaks during daytime -- however, various important exceptions are found.

The dominant feature of the oceanic diurnal cycle is a rainfall maximum in lateevening/early-morning (LE-EM) hours, while over land the dominant maximum occurs in the mid- to late-afternoon (MLA). In conjunction with these maxima are pronounced seasonal variations of the diurnal amplitudes. Amplitude analysis shows that the diurnal pattern and its seasonal evolution are closely related to the rainfall accumulation pattern and its seasonal evolution. In addition, the horizontal distribution of diurnal variability indicates that for oceanic rainfall there is a secondary MLA maximum, co-existing with the LE-EM maximum, at latitudes dominated by large scale convergence and deep convection. Analogously, there is a preponderance for an LE-EM maximum over land, co-existing with the stronger MLA maximum, although it is not evident that this secondary continental feature is closely associated with the large scale circulation. The ocean results clearly indicate that rainfall diurnal variability associated with large scale convection is an integral part of the atmospheric general circulation.

Phase analysis reveals differences in regional and seasonal features of the diurnal cycle, indicating that underlying forcing mechanisms differ from place to place. This is underscored by the appearance of secondary ocean maxima in the presence of large scale convection -- along with other important features. Among these, there are clear-cut differences between diurnal variability of seasonal rainfall over the mid-Pacific and Indian ocean basins. The mid-Pacific exhibits double maxima in Spring and Winter but only LE-EM maxima in Summer and Autumn, while the Indian ocean exhibits double maxima in Spring and Summer, while only a LE-EM maximum in Autumn and Winter. There are also evident daytime maxima within the major large-scale marine stratocumulus regions off the west coasts of continents. The study concludes with a discussion concerning how the observational evidence either supports or repudiates possible forcing mechanisms that have been suggested to explain diurnal rainfall variability. 


\subsection{Introduction}

Diurnal variation of precipitation was first reported in the early 20th century by Hann (1901) and since that time has spawned an immense literature. In general, rainfall maxima in the late-evening/early-morning hours (LE-EM) have been reported for open ocean environments (e.g., Kraus 1963; Gray and Jacobson 1977; Albright et al. 1985; Randall et al. 1991; Imaoka and Spencer 2000), while mid- to-late afternoon (MLA) maxima are often reported for land (e.g., Ray, 1928; Wallace 1975; Kousky 1980; Hamilton 1981; Garreaud and Wallace 1997). However, such generalities do not describe all the intricacies inherent to rainfall's diurnal cycle, and both past observational rainfall datasets and cloud parameterizations in physical models have often lacked the necessary completeness and reliability to ensure dependable analyses; see e.g., Liu and Moncreiff (1998) and Lin et al. (2000) for different perspectives on this topic.

The main scientific objective of this study is to improve our current understanding of diurnal rainfall variability by analyzing the newest and most reliable global-scale satellite data being acquired from the Tropical Rainfall Measuring Mission (TRMM); see Simpson et al. (1996) and Kummerow et al. (2000) for mission and results overviews. In doing so, we seek to explain how large scale and local forcing mechanisms at work over both land and ocean, but in distinct manifestations, produce coherent diurnal variations in rainfall -- to the extent that the TRMM observations spatially and temporally resolve the underlying variations. However, before taking up the analysis, it is worthwhile to consider a number of past results.

Diumal variability of precipitation has long been reported to exhibit distinct spatial variations. For example, Albright et al. (1985) found a morning rainfall maximum in the intertropical convergence zone (ITCZ) of the central and eastern tropical Pacific ocean and an afternoon rainfall maximum in the southern Pacific convergence zone (SPCZ). Gray and Jacobson (1977), in studying the diurnal variability of rainfall over tropical oceans, suggested a coupled radiative-dynamics mechanism to explain the LE-EM maximum within deep cumulus convection. However, they also found that the 1974 GARP Atlantic Tropical Experiment (GATE) radar measurements in the eastern Atlantic exhibited heaviest rainfall during late morning to early evening periods, in conjunction with a LE-EM minimum. This means that the eastern Atlantic's heavy rainfall maximum occurs $\sim 6$ hours later than many other oceanic regions. If such an offset of the dominant rainfall maximum is real, that region's diurnal control is likely some other distinct mechanism. Gray and Jacobson (1977) suggested it could be 
associated with the relatively stronger degree of low level vertical wind shear in the eastern Atlantic tropics and the consequent frequent appearance of squall lines and other types of line convection. They also noted it could be due to the affinity for that part of the ocean tropics to maintain diurnally-driven weather systems originating over continental west Africa -. propagating out over the open ocean as incipient easterly waves. Other mechanisms have been investigated which would transfer diurnal variability from local to remote sources through wavelike propagation of upper tropospheric convergence-divergence patterns (e.g., Silva Dias et al. 1987), or land to ocean gravity wave dispersion (e.g., Yang and Slingo 2001).

Diurnal cycles are manifested in many meteorological variables as numerous studies have reported. These include: (1) surface fluxes of sensible and latent heat over land (Wallace and Hobbs 1977); (2) horizontal winds (Roll 1965, Bonner 1968, Wallace and Todd 1974); (3) large scale horizontal moisture fluxes (Benton and Estoque 1954, Rasmusson 1968); (4) large scale mass divergence and vertical motion (Nitta and Esbensen 1974, McBride and Gray 1980, Sui et al. 1997); (5) surface pressure (Haurwitz and Cowley 1973); (6) cloudiness (Lavoie 1963, Short and Wallace 1980, Meisner and Arkin 1987, Warren et al. 1986); (7) satellite infrared (IR) fluxes (Reed and Jaffe 1981, Murakami 1983, Fu et al. 1990, Janowiak et al. 1994, Faysash and Smith 2000); and (8) outgoing longwave radiation (Duvel and Kandel 1985, Liebmann and Gruber 1988). All these past studies testify, in some fashion, to the meteorological influence of diurnally regulated solar or diabatic heating on either surface or atmospheric processes.

It is generally accepted that an afternoon rainfall maximum over continents is due to land surface heating (LSH), i.e., to the daily solar heating cycle of the relatively low heat capacity land surface in which there is a phase shift between the sun's maximum elevation angle and the peak skin temperature at the surface (see Pielke 2002). A classic result of such a diurnal control is the sea breeze cloud front (SBCF), a major coastal feature particularly recurrent at lower latitudes where strong differential heating over land-sea or land-lake boundaries takes place during the course of a diurnal period.

In contrast, two separate mechanisms have been touted to explain the morning rainfall maximum over oceans. The first may be called the "static radiation-convection" (SRC) interaction, a mechanism which presumes that increased cloud-top IR cooling at night (stemming from the lack of cloud-top solar absorption) and a consequent increase in the thermal lapse rate (e.g., Kraus 1963, Lavoie 1963, Ramage 1971), leads to stronger convection and rainfall at night. 
[Tropical forecasters often refer to this as the "early morning precip max" resulting from enhanced nighttime cloud-top cooling.] This mechanism suggests that radiative forcing tends to favor more intense rainfall during the late night period, provided pre-existence of cloudiness. However, there are problems with this mechanism in explaining diurnal variability in deep convective environments because significant differences between daytime-nighttime oceanic lapse rates are not observed (e.g., Betts 1982, Emanuel 1986, Xu and Emanuel 1989, Emanuel 1994), and the troposphere may actually become stabilized from deep cumulus layer overturning (e.g., Rupprecht and Gray (1976), Gray and Jacobson 1977). Nonetheless, this is the favored mechanism proffered in a comprehensive general circulation model (GCM) study on cloudiness by Randall et al. (1991), noting that in a later related study, Lin et al. (2000) reported that diurnal phasing in that same model is very sensitive to a specified parameter which links cumulus kinetic energy to cloud mass flux.

The second mechanism may be called the "dynamic radiation-convection" (DRC) interaction, which is based on the assumption that day-night differences persist in atmospheric radiative cooling over deep convection regions in conjunction with surrounding clear-air regions. This process suppresses convection during daytime, resulting in more rainfall at night. Daytime suppression results from the outer clear regions undergoing less subsidence warming in response to ongoing radiative cooling because of increased daytime radiative heating from water vapor absorption, thus reducing convergence into the convection region and inhibiting daytime convective growth. This mechanism was proposed by and Gray and Jacobson (1977) and later supported by Foltz and Gray (1979), McBride and Gray (1980), and Ackerman and Cox (1981). However, this process is only appropriate to extended organized convection (such as mesoscale convective systems, tropical cyclones, and large scale convergence zones) where background subsidence can be altered at relatively large scales. In any case, and regardless that both SRC and DRC diurnal interactions are rooted in daytime-nighttime radiative cooling differences, the two mechanisms are diametrically opposed in explaining which portion of the diurnal cycle is most perturbed by the underlying forcing mechanism. In essence the SRC interaction favors nighttime enhancement through increased thermodynamic instability, while the DRC interaction favors daytime suppression through decreased daytime convergence into the convective region.

Actually, a third dynamically-related mechanism has been suggested from a modeling study which considers the oft-noted tendency for hurricanes to undergo nighttime intensity 
amplifications. The study by Tripoli (1992) reports that enhanced nighttime cloud-top infrared cooling destabilizes the cloudy outflow layers and anvil portions of a hurricane, enabling gravity wave energy generated in the lower troposphere in and around the eyewall to be more efficiently transmitted upward through the hurricane, i.e., inhibiting gravity wave absorption which otherwise helps spread anvil cloudiness that stabilizes the precipitation region through increased solar heating during daytime -- i.e., gravity wave trapping in cloud anvils (GWTA). The results suggest that GWTA tends to de-intensity hurricanes by breaking up their organized circulation, i.e., akin to putting out fires in oil wells by internally exploding them. Notably, the mechanism of gravity wave dynamics influencing diurnal cloud and rainfall variability has attracted much attention of late (e.g., Warner et al. 2003 and Mapes et al. 2003b), although a number of ongoing studies concerning ducted gravity waves modulating diurnal rainfall are not yet published.

Other studies that offer differing mechanisms to explain diurnal rainfall variability include: (1) day-night boundary layer wind oscillations (BLWO) over land (Blackadar 1957, Holton 1968, Wallace 1975); (2) day-night differences in large-scale continental heating (LSCH) modulating upper tropospheric divergence (Silva Dias et al. 1987); and (3) semidiurnal tidal mode (SDTM) or $\mathrm{S}_{2}$ pressure wave oscillations (Brier and Simpson 1969, Haurwitz and Cowley, 1973, Hamilton 1981). However, these mechanisms do not explain the large scale pervasive diurnal variability observed in precipitation, particularly over oceans, and in the case of the latter mechanism, Lindzen (1978) suggested that pre-existing diurnally modulated latent heating stemming from precipitation itself must be called for to modify the phasing of pure $S_{2}$ tidal oscillations to match the times of observed tidal extremes.

On top of these primary mechanisms and as noted above, various observational studies have found that a secondary maximum in rainfall occurs during the afternoon over oceans, e.g., Gray and Jacobson (1977), McGarry and Reed (1978), Reed and Jaffe (1981), Augustine (1984), and $\mathrm{Fu}$ et al. (1990). The modeling results of Anderson et al. (1996), Weller and Anderson (1996), and Sui et al. $(1997,1998)$ all support the argument for this secondary oceanic feature. The latter study emphasize that boundary layer forcing from diurnal variation of sea surface temperature (SST) can give rise to an afternoon maximum if convective conditions are in an undisturbed state, but transform to an LE-EM maximum under disturbed convective conditions. This is referred to the OSH mechanism, analogous to the LSH mechanism but over ocean. 
The Sui et al. $(1997,1998)$ studies also draw attention to two factors which should always be considered in defining the timing controls on diurnal cloud-precipitation variability, these being the ambient precipitable water (PW) or relative humidity, and the cloud-storm life cycle process itself that microphysically evolves over time to produce precipitation conditions. Based on TOGA-COARE data, they found that a nocturnal precipitation mode can be explained by relatively more available condensed moisture at night due to diurnally varying radiative cooling (peaking during nighttime) with the resultant change in tropospheric moisture stimulating condensation under disturbed convective conditions. This mechanism, referred to as SRCM and supported in the earlier modeling studies of Tao et al. $(1993,1996)$, is in contrast with the Randall et al. (1991) SRC explanation which suggests that the key diurnal control leading to early morning oceanic precipitation maxima is nighttime thermodynamic destabilization, following suppressed afternoon convective conditions from clouds absorbing solar radiation, enabling destabilized nighttime lapse rates (given sufficient time) to produce enhanced early morning precipitation.

In fact, various studies have emphasized that the morning maximum in precipitation is mostly a timing issue related to events that take place at the time of the previous afternoon's peak solar heating period -- regardless of whether the environment is oceanic or continental (e.g., Mapes and Houze 1993, Chen and Houze 1997, Sherwood and Wahrlich 1999). However, with the exception of the Dai (2001) study that explained a morning maximum in drizzle and light rain over land arising from enhanced nighttime radiative cooling and concomitant relative humidities, and thus requiring time evolution (referred to as SRCL mechanism) -- there is no widely accepted explanation for a LE-EM mode over land. However, such secondary maxima have been observed -- e.g., see the comprehensive raingauge study of Oki and Musiake (1994).

Another process that has been suggested as a mechanism for producing oceanic diurnal rainfall variability is large scale vertical motion (e.g., McBride and Gray 1980). Since variability of PW is generally associated with large scale vertical motion, a combination of vertical motion and ambient moisture conditions can produce diurnal variability, presuming the large-scale vertical motion is itself diumally modulated. However, it is the release of latent heat from precipitation that generally drives large scale modulations in vertical overturning. That is, the diurnal cycle of large scale vertical motion is the result of diurnal rainfall variability rather than the cause -- notwithstanding the case of large scale continental processes inducing oceanic 
vertical motions by remote means as studied by Silva Dias et al. (1987), and also recognizing that remote control processes can be relevant along coasts but not over the deep ocean.

In fact, as mentioned earlier, the recent studies of Mapes et al. (2003a-b) and Warner et al. (2003) investigated how gravity waves excited at a diurnal period by direct-thermal, coastalinterior surface forcing (i.e., the LSH mechanism producing an on-shore afternoon maximum), radiate diurnal oscillations offshore, but delayed to a LE-EM mode by the phase speed of gravity wave propagation across a coast -- a mechanism we refer to here as GWPC. The identification of this mechanism, which is an important corollary to the GWTA mechanism identified by Tripoli (1992), corroborates earlier conclusions offered by Yang and Slingo (2001) who did not present any detailed analysis but recognized the existence of the GWPC process.

Table 1 summarizes the principal mechanisms that have been published (and addressed in the above discussion) to explain diurnal variability of rainfall, a synopsis which we will come back to in the section containing final conclusions. [This compilation may not be exhaustive.]

\subsection{Advent of Comprehensive Satellite Datasets}

Given the historical scarcity of in situ rainfall measurements over ocean, satellite rainfall estimates have been used to provide more uniform and continuous data for investigating oceanic rainfall variability. Over the past two decades, a number of precipitation retrieval algorithms have been developed for various satellite instruments, the predominant techniques being applied to geosynchronous IR (GEO-IR) measurements and passive microwave (PMW) radiometer measurements. However, until recently, significant uncertainties in the retrieval products of satellite remote sensing techniques have undermined their applicability to rainfall variability analysis. Before the launch of TRMM on November 27, 1997 (Thanksgiving Day in the United States), the most reliable estimates of instantaneous precipitation had been generated from Special Sensor Microwave/Imager (SSM/I) PMW measurements (e.g., Wilheit 1994; Ebert and Manton 1998; Smith et al. 1998; Yang and Smith 1999). SSM/I radiometer measurements are obtained from Defense Military Satellite Program (DMSP) platforms, satellites notionally flown in pairs within separate (phase-shifted) sun-synchronous orbit planes. Although quantifying diurnal variability from one or two sun-synchronous orbiters is a marginal exercise, by extended averaging Chang et al. (1995) found clear-cut differences in annual mean ocean rainfall based on morning and evening passes of SSM/ $/ \mathrm{m}$ measurements. They found morning rainfall to be about $20 \%$ greater than evening rainfall, with most significant differences occurring along the ITCZ. 
Our study is motivated by the new meașurements from the TRMM satellite, whose nonsun-synchronous orbit was explicitly selected to provide diurnal sampling capability. TRMM's orbit plane is inclined $\sim 35$ degrees with respect to the Earth's equatorial plane. It was inserted into an orbit altitude of $\sim 350 \mathrm{~km}$ after its launch in November'97, then lifted to an altitude of $\sim 400 \mathrm{~km}$ in August-2001 to preserve fuel for extended life.

Studies of the diurnal variability of rainfall prior to the TRMM era, whether they were based on in situ (raingauge, radar) or satellite (GEO-IR, sun-synchronous PMW) datasets, were always restricted by some type of spatial or temporal sampling limitation -- even overlooking inherent problems in the retrieval process for non-microwave satellite methods. Therefore, a comprehensive understanding of diurnal precipitation processes at global scale has been lacking. With diurnal sampled measurements intrinsic to TRMM's non-sun-synchronous orbit, and the high quality, uniform, and consistent precipitation products over the $\pm 35^{\circ}$ latitude zone being produced by three standard level 2 rainrate retrieval algorithms applied to TRMM Microwave Imager (TMI) and TRMM Precipitation Radar (PR) measurements (see Okamoto 1988, Nakamura 1990, and Kummerow et al 1998 for descriptions of the TRMM instruments), an improved understanding of global rainfall diurnal variability has now gradually begun to emerge. Ongoing intercomparison analyses being conducted at the NASA/Goddard Space Flight Center (GSFC) by the authors, involving results from the three standard level 2 algorithms (i.e., the TMI-only, PR-only, and TMU/PR Combined algorithms) now indicate agreement within $10 \%$ on a global-annual average scale. Using retrieved datasets from the three standard level 2 rainrate retrieval algorithms for the 1998 annual cycle, this investigation initially demonstrates that the diurnal properties of the three sets of retrievals are consistent. [This lends credibility to the diurnal analyses of the non-homogeneous space-time properties of diurnal rainfall variability.] Thereafter, systematic analyses of diurnal rainfall processes over land and ocean are carried out, with a focus on explaining the various control mechanisms at work producing the variations.

Hereafter, section 3 describes the analysis methodology while section 4 describes the various TRMM datasets. Section 5 then presents analysis results for the large scale at three distinct time scales (day-night, 3-hourly, monthly), followed by section 6 presenting analysis results at the seasonal time scale. Section 7 provides final discussion and conclusions. 


\subsection{Methodology}

The TRMM satellite is equipped to measure rainfall within the 35 degree north-south latitude parallels (Simpson et al. 1996). There are approximately 16 orbits per day with approximately 92 minutes between orbits. Since only the TMI's wide-swath scan (780 km) provides measurements much beyond the $\pm 35^{\circ}$ latitudes, only those retrievals within the $35^{\circ}$ latitude orbit inclination limits are used. Due to the nature of the TRMM orbit which samples a given spot approximately 26 times per month at the equator (slightly increasing at higher latitudes), some type of space-time averaging must be performed to obtain representative diurnal quantities. Therefore, in this study we use a $5^{\circ} \times 5^{\circ}$ latitude-longitude grid, a time resolution of 3 hours, and a monthly accumulation scale to analyze the diurnal variability. Sensitivity tests indicate this approach stabilizes the diurnal statistics. Moreover, it is worth noting that any residual sampling error in the analysis is further reduced when considering purely daytime/nighttime differences (i.e., 12-hour temporal scale), or 3-hourly resolved seasonal and annual scales. All these various averaging scales are employed in the proceeding analyses.

The spatial-temporal properties of diurnal rainfall variability over a sequence of annual cycles are important to a full understanding of a precipitation climatology and the underlying interannual variability. For specific analyses, in order to quantify the underlying structures in an objective fashion, 3-hourly diurnal rainfall time series at a given grid point for a given accumulation period (i.e., 1-month, 3-month, or 12-month) are expressed by the amplitudes and phases of the 1st Fourier harmonic of a given series containing eight 3-hourly samples. Grids of amplitude and phase factors then provide global scale fields of intensities and event times of daily peak rainfall. In this fashion, the combination of amplitude and phase factors objectively decomposes the salient space-time properties of variable diurnal rainfall.

\subsection{Description of Datasets}

Precipitation retrievals from TRMM's standard algorithms provide the most accurate rainfall from spaceborne remote sensing, as acknowledged in various blended precipitation algorithm studies which use TRMM retrievals as the primary satellite calibration standard (e.g., Huffman et al. 2001 and Turk et al. 2004), and other types of studies depending on inherent accuracy and precision in the retrievals (e.g., Simpson et al. 1998, Hou et al. 2000, Short and Nakamura 2000, and Tao et al. 2004). The three standard TRMM rainfall algorithms whose 
retrievals are used in this study are called 2a12: (TMI-only), 2a25 (PR-only), and 2b31 (PR-TMI Combined) -- all of which are referred to as standard level 2 (instantaneous) profile algorithms.

The 2al2 algorithm is TRMM's main TMI-only level 2 profile scheme, which uses cloud model-generated microphysics as the solution-basis for microphysical profiling. The algorithm is cast in Bayesian form to expedite RTE inversion calculations, accounting for non-uniform beam filling through an assumed distribution of rainrates within a given beam area (Kummerow et al. 1996, 2000). There are actually two distinct retrieval schemes intrinsic to $2 \mathrm{a} 12$, an ocean component which derives most of the rainrate profile solution from TMI's low frequency emission channels, and a land component which is based on TMI's high frequency scattering channels. The $2 \mathrm{a} 12$ algorithm retrieves over a wide-swath domain, denoting that it produces rain coverage over an $\sim 780 \mathrm{~km}$ wide track swept out by the conically-scanning TMI radiometer.

The $2 a 25$ rainrate $(R)$ algorithm is the main PR-only profile retrieval scheme, using a retrieval technique akin to a Hitschfeld and Bordan (1954) inversion solution for a vector of attenuated reflectivity factors $(Z)$ assigned to a sequence of range-gates (Iguchi and Meneghini 1994, Iguchi et al. 2000). It also uses a PR-based climatology of cloud-free surface radar crosssections $\left(\sigma_{\mathrm{r}}\right)$ to ultimately prescribe path attenuation (A) profile properties if a measured nearsurface range-gate $\mathrm{Z}$ factor is not reconciled by the downward accumulated Hitschfeld-Bordan generated total path attenuation (TPA). This adjustment involves the surface reference technique (SRT) developed by. Meneghini et al. (2000); also see Meneghini and Kozu (1990). This means that if the initial top-down TPA estimated from a unified pair of Z-R and Z-A relationships used in the rainrate conversion equations do not satisfy the measured $Z$ factor measured just above the surface, the power law coefficients intrinsic to the Z-R and Z-A relationships are adjusted to ensure that the final $R$ and A profiles give rise to the TPA directly estimated from the SRT. The 2a25 algorithm retrieves over a narrow-swath domain, denoting that it produces rain coverage over an $\sim 220 \mathrm{~km}$ wide track swept out by the crosstrack-scanning PR instrument.

The $2 \mathrm{~b} 31$ algorithm is TRMM's standard PR-TMI Combined instrument profile scheme based on an elaborate Bayesian modification to the $2 \mathrm{a} 25$ retrieval solution - augmented with an additional estimate of total path attenuation derived from TMI's $10.7,19$, and $37 \mathrm{GHz}$ channels. This provides the Combined algorithm with three distinct and ordered Bayesian sweeps for evaluating the attenuation profile: (1) top-down Hitschfeld-Bordan generated As; (2) SRTgenerated As, and (3) TMI-generated As. The microphysical database supporting the Z-R and Z- 
A matrices used in the Bayesian calculations are derived from disdrometer observations made in Darwin, Australia and during the west Pacific. TOGA-COARE field program. The spatial, temporal, and angular beam discrepancies between the PR and TMI instruments are partially reconciled through a deconvolution procedure, such that rainrate estimates are taken at $\mathrm{PR}$ resolution. The $2 \mathrm{~b} 31$ algorithm has been described by Haddad et al. (1997) and Smith et al. (1997). It is referred to as a "tall" vector scheme, stemming from its use of all PR-measured Zs from a rain-gate vector and a vector of radiometer-measured brightness temperatures (TBs) over the cm-mm spectrum. By combining two non-similar vectors in an "instrument-balanced" concatenated inversion scheme, the notion of an extended or "tall" vector is denoted. Since the 2 b31 scheme uses PR measurements, it is necessarily a narrow-swath algorithm.

The rainfall retrievals used in the study are the pixel-resolution surface rainrates from the above three standard level 2 TRMM algorithms. The TRMM algorithms have evolved through three (3) level 2 versions since the launch of the TRMM satellite. The launch versions are referred to as V4, the current versions V5, and the new but yet to be processed versions V6. At the time this study was completed, one test month of data had been reprocessed with the V6 algorithm, i.e., February 1998. Results from that month have been used to prepare the diagrams presented in Figures 1 and 2 (to be discussed in section 5). The remaining results were produced from the previous versions (i.e., Table 2 and Figures 3 through 14). However, sensitivity tests were conducted to ensure that all results obtained from the previous version are only marginally changed in transferring to the V6 refinements.

Full resolution rainrates are assigned to $5^{\circ}$ by $5^{\circ}$ latitude-longitude grid meshes for each TRMM orbit. Then all pixels within each grid box are accumulated over a month for the selected time intervals of 3-hour and daily -- including 12-hour daytime and nighttime. A mean rainrate for each grid box is given by the total rainrate accumulation divided by the total pixels assigned to the box. This procedure is also applied to seasons whenever seasonal diurnal rainfall variations are under consideration (i.e., the diagrams of Figures 9 through 14). 


\subsection{Large Scale Diurnal Variability}

Conerent precipitation variations occur over a range of time scales from semi-diurnal to decadal. Ultimately, all of these variations are important in the context of weather, climate, and hydrology, and thus it is important that all of these modes of variability are understood, measured, and hopefully at some point in the future, reproduced in environmental models. Because diurnal variability is such a pronounced component, it has the possibility of resonating with variational modes at other time scales -- and thus has to be given careful attention.

\subsection{Day-night variations}

At the diurnal time scale, day-night variation is the prominent variability mode over most regions of the Earth. Figures 1a-b illustrate maps of day and night rainfall accumulations for February 1998 from the latest versions (V6) of the three level 2 TRMM standard algorithms 2a12 (TMI-only), 2a25 (PR-only), and 2b31 (PR-TMI Combined). At the planetary scale, the day and night rainfall distribution patterns for all three algorithms are similar, which bodes well for deriving conclusions concerning monthly-scale diurnal variability from any individual algorithm. Inspection also reveals that the macroscale rainfall distribution patterns from day to night for any given algorithm are similar, with the most significant regional-scale day-night variations concentrated within the climatologically heavy rainfall regions, particularly the ITCZ, the SPCZ, the major rain forest regions, the Australian monsoon, and those portions of the baroclinic storm tracks which are under TRMM coverage. Qualitatively, it is not apparent from Figs. 1a-b whether any particular algorithm tends to run higher or lower than the others, therefore this issue is addressed quantitatively below. It is also not immediately apparent whether any given algorithm exhibits greater or lesser day-night changes, although each algorithm tends to exhibit its own unique regional features in this regard. Perhaps the most notable region where all three algorithms exhibit fairly dramatic day-night changes is within the V-like intersection of the ITCZ and SPCZ -- referred to hereafter as the "V-sector".

Regardless of detailed day-night differences amongst the algorithms, the near-equivalent distribution patterns indicate that both narrow-swath $(2 \mathrm{a} 25,2 \mathrm{~b} 31)$ and wide-swath (2a12) algorithms at the monthly scale are in close agreement vis-à-vis rain coverage for the two 12 hour diurnal periods. As noted, the rainfall distribution patterns for the day and night periods are 
similar at the tropical macro-scale -- although not equivalent. On the other hand, day-night diurnal amplitudes are considerably different for specific regions.

Figure 2 depicts the spatial distribution of the ratio of daytime to nighttime rainfall accumulations (from Figs. 1a-b) for algorithm 2a25. [The ratio patterns for $2 \mathrm{a} 12$ and $2 \mathrm{~b} 31$ (not shown) are virtually identical.] The main features evident in this diagram are: (1) major portions of the continents indicate values greater than 1.0, signifying more daytime than nighttime rainfall over those regions; (2) major portions of the oceans indicate values less than 1.0, signifying more nighttime than daytime rainfall; (3) portions of the oceans indicate daytime maxima (ratios > 1.0), particularly eastern basins off the west coasts of continents which exhibit coherent daytime maxima (and where extensive marine stratocumulus clouds fields persist), as well as other isolated ocean features such as the mid-Pacific Ocean, the southwest Indian Ocean, the central Atlantic Ocean, the eastern Caribbean Sea, the north Pacific, and the southeast Pacific; and (4) coherent regions over various continents exhibit nighttime maxima (ratios $<1.0$ ), mainly subtropical Africa, Australia, and South America, as well as eastern tropical South America. Over oceans, regions where ratios exceed 1.0 (daytime maxima) generally exhibit weak rainfall (with the exception of the persistent marine stratocumulus areas), and conversely for continents, regions where ratios fall below 1.0 (nighttime maxima) generally are subtropical. There are various small areas where ratios exceed 1.0 which are the result of retrieval noise, i.e., when small-value nighttime denominators are accompanied by insignificant differences in day-night values, but with the noise-contaminated denominators slightly smaller than the correspondingly small and noisy daytime numerators (i.e., regions of very little rainfall accumulation). Overall, however, there are more areas where nighttime rainfall exceeds daytime rainfall over oceans in statistically significant terms, with the opposite behavior over continents.

Insofar as the marine stratocumulus zones, these results clearly indicate that the associated rainfall, which is largely drizzle and warm rain, peaks during daylight hours. Although counterintuitive to some who argue from a modeling perspective that stratocumulus drizzle is largely a nighttime phenomenon peaking some time after the daytime process of solarinduced convective erosion of stratocumulus cloud decks has been produced by the warmed cloud layer and thermodynamic decoupling (see Turton and Nicholls 1987, Rozendaal et al. 1995, and Garreaud and Muñoz 2004 for studies of the afternoon cloud minimum), the diurnal properties of ocean stratocumulus drizzle have never been thoroughly observed and documented. 


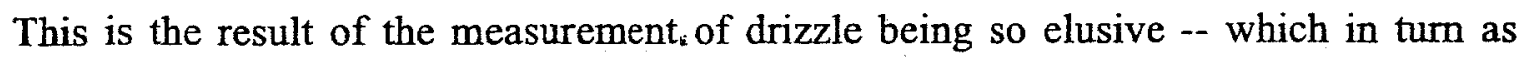
upheld a consistent theory involving the diurnal behavior of both cloudiness and rainfall. Regardless, there is observational evidence for a daytime maximum. For example, Ciesielski et al. (2001) found for Atlantic Stratocumulus Transition Experiment (ASTEX) data, that even with the nighttime maximum in cloudiness, the daytime boundary layer exhibits significantly greater water vapor mixing ratios. Therefore, and with some caution because TRMM algorithms exhibit their greatest uncertainties at the light end of the rainrate spectrum, these new results suggest that marine stratocumulus rainfall coherently peaks during daytime throughout all ocean basins.

To better quantify algorithm-to-algorithm differences, and concomitantly their consistency in representing bulk diurnal rainfall behavior, the mean monthly-zonal daytime and nighttime rainfall accumulations over ocean and land are examined for the entire 1998 calendar year (figures not shown). Over ocean for Jan'98, algorithm 2a25 generates the lowest totals while $2 \mathrm{a} 12$ generates the highest. Over land for the same month, algorithm $2 \mathrm{a} 25$ again generates the lowest totals while $2 \mathrm{~b} 31$ generates the highest. [These same minima-maxima are found for the Feb'98 V6 results.] However, regardless of these magnitude differences, the zonal patterns are structurally similar. For January, the peak of heavy rainfall over ocean is confined within the $0-5^{\circ} \mathrm{S}$ equatorial band, but with large values on either side progressively decreasing into the subtropics. Over land, the heavy rainfall peak is spread out over a wider zone, between Eq- $25^{\circ} \mathrm{S}$. Over ocean, the day-to-night zonal average ratios are generally less than 1.0 for the heavy rainfall zones. Over land, the patterns of the day to night zonal average ratios are more complicated. Although most ratios exceed 1.0 in the heavy rainfall regions, there is no distinct heavy rainfall zone between $20-10^{\circ} \mathrm{S}$ in which ratios are significantly less than 1.0. This is akin to ocean behavior and denotes a second mode of variability over the continents mimicking the primary ocean mode -- although it is presumed that the cause of the nighttime continental mode may be different than that of the nighttime oceanic mode. Overall it is found that there is greater intermittency in the primary diurnal regulation process over land in conjunction with its major MLA maximum, than there is over ocean in conjunction with its major LE-EM maximum.

These analyses have been conducted for the other months of 1998 with each set of monthly results indicating the same basic diurnal phenomena, distinguished only by the seasonally evolving spatial distributions of the heavy rainfall regions. 


\subsection{Mean monthly diurnal cycle at 3-hour time scale}

Figures 3a-b illustrate the 3-hourly evolution of the spatial distribution of accumulated rainfall for January 1998 based on algorithm 2al2. The large scale spatial patterns from period to period have obvious similarities, but overall, they describe a dynamically changing situation -largely produced by diurnal variations in rainfall intensity in the heavy rainfall regions and associated variations in the locations of the relative maxima. For example, over the Indian and Pacific oceans, there are major peaks in the early morning period between 03-06 Mean Solar TIME (MST) -- i.e., the LE-EM mode. Also, there is a secondary peak over the Pacific in the 15-18 MST period -- the MLA mode. The tropical eastern Atlantic exhibits a late morning maximum between 09-12 MST, a feature described by Gray and Jacobson (1977) as a delayed oceanic morning rainfall maximum. Further inspection reveals additional major differences in rainfall peaks over the eastern and western Indian ocean tied to a diurnally-intermittent east-west dipole; there are similar processes taking place over the western and central Pacific ocean. Over central South America, the major peak takes place between 18-21 MST, occurring right after the nominal MLA mode, with a significant secondary peak occurring in the 06-09 MST period -corresponding to the LE-EM mode. Over southern Africa, two diurnal peaks are also evident in the 15-18 and 03-06 MST periods -- modes corresponding to the two found over central South America. [These same peaks are found in the $2 \mathrm{a} 25$ and $2 \mathrm{~b} 31$ results.]

To more clearly emphasize the roles of oceans and continents in organizing the global scale pattern of diurnal rainfall variability, Figure 4 presents the diurnal-longitude cross-section for Jan'98, again for algorithm 2a12, averaged over the boreal winter's heavy rainfall zone of Eq- $15^{\circ} \mathrm{S}$. This diagram reveals an east-to-west sequence of early morning peaks, almost all over ocean, and a less clearly defined sequence of afternoon peaks, with each major continental area in the southern hemisphere (Africa, Maritime Continent, South America) exhibiting relative maxima along with other afternoon relative maxima situated over various sectors of the Indian and Pacific oceans. There is a suggestion of eastward transiting wave behavior in the western Pacific, although it is subtle.

To elucidate the primary modes of monthly diurnal variability but resolved over a spatial grid, Fourier analysis is applied to the Jan'98 results for all three level 2 algorithms to produce a diurnal amplitude-phase framework. On a $5^{\circ}$ by $5^{\circ}$ deg lat-lon grid mesh, the first Fourier harmonic is extracted for each grid cell along with its respective amplitude and phase factors. 
Mapping the amplitude factors, as shown in Figure 5a, enables an examination of the varying intensity of the primary diurnal harmonic. One of the more salient features of this diagram, and quantified in Table 2 with correlation analysis, is that all three algorithms, although not in complete agreement in terms of amplitude intensity, are in considerable agreement insofar as the spatial distribution of the largest amplitudes. [The amplitude differences arise from two sources: (1) overall systematic differences between the algorithms, and (2) the fact that 2 al2 wide-swath coverage is three times that of $2 \mathrm{a} 25$ and $2 \mathrm{~b} 31$ narrow-swath coverage -- noting that $2 \mathrm{a} 25$ and $2 \mathrm{~b} 31$ are in greater agreement with each other than either is to 2a12.] Another key feature is that the spatial pattern of the strongest amplitudes largely mimics that of the heavy rainfall pattern. Regardless of whether this arises from statistical principles or from physical necessity, it is important at this stage to recognize that strong diurnal variability couples with heavy rainfall.

The map of phase factors associated with algorithm 2a12's amplitudes is illustrated in Figure 5b. Phase is plotted in units of diurnal time, i.e., the hour associated with the rainfall maximum of the 1st Fourier harmonic. The diagram also uses shading to denote the regions exhibiting the largest amplitude factors, i.e., regions where the phase information is perhaps most important insofar as diurnal rainfall activity. [As with amplitudes, the spatial patterns of phase factor for the other two algorithms are similar - see Table 2.] An evident feature of the phase distribution is that the timing of the daily rainfall maximum is a heterogeneous variable. However, most ocean regions indicate some type of coherent morning maximum, with a notable exception in the tropical central Pacific just west of the date line, where a coherent afternoon maximum is located -- consistent with what Augustine (1984) found twenty years ago. At the same time, the major continents of Africa, Australia, and South America all exhibit coherent afternoon maxima for significant portions of the strong amplitude regions, and morning maxima for the weak amplitude regions. This mixture of early morning and mid-afternoon maxima over both oceanic and continental domains, in which land areas exhibit the greatest heterogeneity, must be considered a fundamental property of rainfall diurnal variability.

\subsection{Annual evolution of mean-monthly diurnal variation}

Figures $6 a-b$ illustrate diurnal-month cross-sections of rainfall over oceanic and continental regions from algorithms 2a12, 2a25, and $2 \mathrm{~b} 31$ extending throughout the 1998 annual cycle. Over oceans, the distribution patterns for the three algorithms are similar, in which a predominant morning rainfall peak during the 03-06 MST period (the LE-EM mode) occurs 
every month with its greatest amplitudes in January, May, August and December. In addition, a secondary MLA peak occurs during the Winter and Spring months. Over continents, a consistent diurnal cycle is also evident for all three algorithms. A MLA peak persists each month with maximum amplitudes occurring during the Autumn and Winter months. As with oceans, there is a secondary LE-EM peak most evident during the months of January and September.

Therefore, primary and secondary diurnal peaks occur over both oceans and continents, with their diurnal phasing reversed. On a monthly time scale, morning rainfall maxima over oceans and afternoon maxima over continents are persistent. The secondary maxima are generally a regular afternoon feature for oceans while a more intermittent morning feature for continents, and tend to exhibit more seasonality in their occurrence than the primary maxima whose amplitudes vary from month-to-month but never disappear.

The most important feature of these month-to-month changes in the diurnal rainfall cycle is the seasonal variation of diurnal intensity, particularly in the large scale convergence zones. To emphasize this point, an analysis of the annual evolution of diurnal rainfall variation has been carried out over the heavy tropical precipitation regions embedded within the equatorial trough zone, including the Asian monsoon precipitation system, and the persistent rainfall portion of the intersecting ITCZ and SPCZ convergence zones. Figure 7a illustrates time-longitude crosssections of diurnal cycle amplitude and phase averaged over the $10^{\circ} \mathrm{N}=10^{\circ} \mathrm{S}$ deep tropical latitudes produced by all three level 2 TRMM algorithms. To facilitate interpretation, the corresponding cross-sections of accumulated rainfall produced by each of the three algorithms is provided in Figure 7b. Each of the amplitude diagrams (left-hand panels of Fig. 7a) consistently indicate strong propagation of the diurnal peak amplitude away from the international date line in the vicinity of the warm pool to the west, with weaker propagation from the same origin to the east. This is in response to the transition from the 97-98 El Niño to the 98-99 La Niña in which the strong active-ENSO convection region over the warm pool diminishes once the large scale zonal circulation cells begin to migrate to their "so-called" neutral configurations.

This evolution of positioning of the peak diurnal amplitudes during 1998 corresponds almost exactly with the evolution of the location of total rainfall within the equatorial trough that same year. As evident in Fig $7 \mathrm{~b}$, there is a migration in the maximum rainfall pattern away from the warm pool to both west and east, i.e., the expected transformation process from an active to an inactive ENSO climate (see Bell et al. 1999 and Trenberth et al. 2002). Moreover, these 
results emphasize that the annual cycle of rainfall diurnal variability is closely associated with the positions of heavy convective rainfall systems developing within the convergence regions of the deep tropics, regions which undergo interannual shifts due to coupled ocean-atmosphere climate-scale perturbations. Another way to describe this variability is to simply note that the ENSO process includes within its multi-faceted governing mechanisms, a strong diurnal component associated with enhanced warm pool rainfall.

Notably, the amplitude distribution patterns in Fig. 7a for each of the three algorithms are consistent. There is a persistent rainfall peak over central-west South America throughout the year with maximum amplitudes in September and October, accompanied by strong amplitudes in the central-east Pacific from February through May. Over the tropical Indian ocean, the diurnal amplitude peaks in May and diminishes in September, with evidence of a monsoon surge-break cycle. There is also a large amplitude region in the west Pacific which exhibits the greatest values throughout the boreal Autumn-Winter-early Spring period when the ITCZ is mainly active within the deep tropics. Once boreal summer commences and the ITCZ both propagates northwards and becomes more intermittent, the diurnal amplitudes diminish. There is also a shift in highest amplitudes from the western end of the tropical west Pacific during Spring towards the warm pool in early. Winter, associated with SPCZ convection and excitation of enhanced convection in the wintertime $\mathrm{V}$-sector. Over the tropical African rainforest, the largest amplitude peaks occur in September in conjunction with the rainy season. Over the equatorial Atlantic, weak diurnal amplitudes occur in December, possibly associated with convective waves.

The corresponding phase distributions are found in the right-hand panels of Fig. 7a. As with amplitudes, the three patterns of phase distribution are consistent. For the high amplitude South American and African regions, the phase values associated with these peak amplitudes are approximately 1200-1500 MST, indicating that the most intense rainfall activity occurs from early to mid-afternoon (or just prior to the MLA mode). Over the tropical Indian ocean from early Summer to mid-Autumn, i.e., during the active southwest monsoon period (May-October), there are rainfall peaks in both the early and late moming (0600-0900 MST / LE-EM mode and 0900-1200 MST), but mostly during the early afternoon (1200-1500 MST). This latter timing is consistent with a delayed early morning ocean mode.

There is a LE-EM peak in the west Pacific during the early part of the year, with this peak transitioning to the central Pacific in the latter part of the year. Conversely, and as 
discussed earlier in conjunction with the Augustine (1984) result, early afternoon peak amplitudes are found in the central Pacific during the early part of the year, with that phase feature shifting to the west Pacific as the year progresses. As with the Indian ocean, this establishes seasonality in how the morning and afternoon diurnal rainfall maxima materialize throughout the deep tropical western Pacific. Similar phenomena are found in the eastern Pacific where morning maxima are most prominent, but there are peak diurnal amplitudes occurring in the early afternoon toward the eastern side of the region throughout July to September. In the Atlantic Ocean, the diurnal maxima can occur anytime from early morning to late morning depending on the time of year. Overall, the diurnal amplitude-phase analysis of the 1998 deep tropics indicates that the fundamental diurnal harmonic of rainfall can exhibit highly localized. geographic properties, but properties in which the most significant features are directly associated with the occurrence of heavy rainfall.

Contrasting differences in diurnal variability between the Indian and Pacific oceans are evident from the above analysis. Additional insight into these differences is given by analysis of the evolution of diurnal variability along the meridional axis. Figure 8a illustrates month-latitude cross-sections of the diurnal amplitude of rainfall variability produced by the $2 \mathrm{a} 12$ algorithm, averaged over the $50^{\circ}-110^{\circ} \mathrm{E}$ (upper panel) and $150^{\circ} \mathrm{E}-150^{\circ} \mathrm{W}$ (lower panel) longitude sectors. It is evident that within the Indian ocean basin (upper panel of Fig. 8a) the maximum amplitude is located at $\sim 7.5^{\circ} \mathrm{S}$ in January, with a persistent relative peak amplitude at that same latitude throughout the year. This corresponds to persistent intraseasonal tropical convective waves that occur over the equatorial Indian ocean; e.g., see Jones et al. (2004). However, the key feature in this diagram is that the peak amplitude of diurnal rainfall variability migrates from its $\sim 7.5^{\circ} \mathrm{S}$ latitude position in January, to an $\sim 15^{\circ} \mathrm{N}$ latitude position in May, propagating further northward to $\sim 18^{\circ} \mathrm{N}$ in mid-June (where the amplitude achieves its maximum value for the year), further northward to $\sim 30^{\circ} \mathrm{N}$ in August, and finally retreating back to an equatorial position in December. This process describes the initiation, progression, and withdrawal of the southwest Indian monsoon but cast in a diurnal rainfall variation framework.

In contrast to Indian ocean variability, diurnal rainfall variability in the central Pacific ocean (Fig 8a lower panel) is characterized by a less extended south-to-north progression over the course of the year. Somewhat similar to the Indian ocean, the maximum amplitude in January is $\sim 10^{\circ} \mathrm{S}$, but over the mid-Pacific, northward propagation extends only to $\sim 10^{\circ} \mathrm{N}$ in 
July, retreating back to $\sim 7^{\circ} \mathrm{N}$ in December. Moreover, and unlike the Indian ocean, a relative maximum re-emerges in the vicinity of $10^{\circ} \mathrm{S}$ in late summer and persists throughout the remainder of the year (August-December), an apparent bifurcation in the maximum amplitude progression. In fact, this process is the manifestation of diumal rainfall variability concurrent with the annual migration of the ITCZ. Although it is not perfectly consistent with the conventional understanding that the annual-climatological ITCZ migration extends from $7^{\circ} \mathrm{S}$ to $10^{\circ} \mathrm{N}$ in the course of an annual cycle (Waliser and Gautier 1993), it is physically consistent with ITCZ migration dynamics. What actually takes place in terms of precipitation variability is first an increase in rainfall during the excitation of the "V sector" in January at $\sim 10^{\circ} \mathrm{S}$, i.e., the amplified merger of the ITCZ and SPCZ that has been described in detail by Vincent (1994). This gives rise to the boreal winter maximum in the southern hemisphere seen in the lower panel of Fig.8a. As boreal spring and summer commence, the ITCZ shifts north in response to the northerly migration of the trade winds needed to satisfy global mass-momentum conservation constraints. There is a concomitant shift in rainfall, and as summer wanes, the ITCZ begins its reverse migration southward. At the same time, the SPCZ begins to reactivate during austral summer - which produces the appearance of bifurcation in propagation activity.

There is an additional high amplitude feature appearing in the $30-35^{\circ} \mathrm{N}$ zone at the end of 1998 during late-summer-early winter (boreal). This represents storm track surges into the subtropics associated with tropical storm activity (see Chang et al. 2002).

The phase distributions associated with the amplitude diagrams given in Fig. 8a are shown in Figure $8 \mathrm{~b}$. Over the Indian ocean (upper panel), the dominant phase peak is latemorning to early-afternoon for spring and summer, while early- to mid-morning for autumn and winter. This describes a shift from a delayed early morning peak to a LE-EM peak, generally consistent with what has been described in the Fig. 7 result. Over the Pacific ocean (lower panel), there is a nearly consistent LE-EM phase peak over the $20^{\circ} \mathrm{S}-20^{\circ} \mathrm{N}$ latitude zone except in the southern hemisphere during January-April. The early year northern hemisphere subtropics exhibits a coherent MLA maximum where rainfall is weak, and an expected symmetric southern hemisphere MLA maximum in the late year. Clearly, the Pacific ocean is the dominant basin of the two insofar as maintaining a LE-EM morning maximum in rainfall within the heavier rainfall region. In essence, the Indian ocean exhibits a LE-EM maximum during its cold season, switching to an early afternoon maximum during its warm season. This localized 
seasonal heterogeneity in amplitude and phase is intrinsic to diurnal rainfall variability, beyond the mean features produced by the primary LE-EM oceanic and MLA continental modes.

\subsection{Seasonal Scale Analysis of Diurnal Variability}

The results presented in the previous section define various coherent modes of diurnal rainfall variability at the monthly time scale, the most salient modes being the primary LE-EM and MLA modes over oceans and continents, respectively, and their associated MLA and LEEM secondary modes. Attention is also given to the delayed early morning mode over ocean and other fluctuations in timing around the primary modes, especially for continental rainfall. Intuitively, the primary oceanic and secondary continental modes would be produced by similar or equivalent physics (supported in part by the Tao et al. 1996, Sui et al. 1997, 1998, and Dai 2001 studies), as would the primary continental and secondary oceanic modes (as Sui et al. 1997, 1998 have suggested). Nonetheless, these parallels have not been objectively proven through the monthly analyses, and as stressed in the introduction, there are various competing theories as to the origin of diurnal variability over oceans and continents.

For example, the Silva Dias et al. (1987) study, the study of Yang and Slingo (2001), and the recent studies of Mapes et al. (2003a-b) and Warner et al. (2003) draw attention to how different surface and atmospheric mechanisms might manifest themselves in transferring diurnal signals from interior continents to coastal regions, and on into oceanic regions. In this regard, it is important to recognize that the results presented in section 5, particularly the diagrams in Figs. 2 and $5 b$, provide concrete evidence that the modes of diurnal variability are spatially heterogeneous on a monthly time scale over both oceanic or continental regions. Presumably, part of the observed heterogeneity is real. However, allowing that part may be due to limitations in TRMM sampling when considering an individual grid box at a spatial scale of order $500 \mathrm{~km}$, it is useful to further mitigate sampling shortcomings by focusing only on the most robust modes. Therefore, this section examines the problem at a seasonal time scale by invoking an averaging period of three months.

\subsection{Global interpretation at seasonal scale}

Figure 9 involves the classic use of the boreal Winter, Spring, Summer, and Autumn seasonal classifications to illustrate how diurnal variability materializes when considering the entire TRMM observation zone. This diagram presents the diurnal variability of rainfall, 
averaged over ocean and land separately from $35^{\circ} \mathrm{S}$ to $35^{\circ} \mathrm{N}$, for the four seasons of 1998 . These results are obtained from TRMM algorithm $2 \mathrm{a} 12$ with the analysis using the standard seasonal definitions: (a) Winter consists of months December, January, and February (DJF); (b) Spring of March, April, and May (MAM); (c) Summer of June, July, August (JJA); and (d) Autumn of September, October, and November (SON).

It is apparent in Fig. 9 that the primary and secondary diurnal modes identified in the monthly analyses are very pronounced in a seasonal analysis. For the ocean, the primary LE-EM mode is clearly evident and strongest during Winter. The secondary MLA ocean mode is also most pronounced during Winter, but is readily apparent in the other three seasons. Over land, the primary MLA mode is strong for all four seasons, particularly for Autumn. In the case of the secondary continental mode, the LE-EM peaks are most apparent for the two transition seasons of Spring and Autumn, and although weaker, still detectable for Winter and Summer, with the Winter season's relative maximum tending towards early morning (EM) as opposed to late evening (LE) -- where it is positioned for the other three seasons. One might argue that the controls on diurnal variability are more complex over the continents because of the greater modulation of the amplitudes in the primary and secondary maxima, but the contrasts in amplitude between the primary Winter ocean mode and its counterparts in the other three seasons tends to negate that argument. In any case, it is evident that there are seasonal fluctuations in the amplitudes of the diurnal maxima for a given mode -- but only minor variations in phases.

\subsection{Regional interpretation at seasonal scale}

Figure 10 is used to show how much global scale coherency in the four prominent modes is preserved at a regional scale. This diagram presents the seasonal diurnal-longitude crosssections for the deep tropics $\left(10^{\circ} \mathrm{S}-10^{\circ} \mathrm{N}\right)$ over the 1998 annual cycle, from algorithm $2 \mathrm{a} 12$. Starting in the Indian ocean: (1) LE-EM peaks clearly occur in this basin, most pronounced in Summer during the peak monsoon period, but sustained for the rest of the year, (2) relatively weak LE-EM peaks and rarer early-evening peaks occur over the Indonesian and far-west Pacific regions, (3) seasonally intermittent but weak LE-EM peaks occur over the central-west Pacific, (4) strong LE-EM and MLA maxima occur in the central-east Pacific, but only during Winter and Spring, (5) a strong LE-EM maximum occurs in the east Pacific during Spring in conjunction with the somewhat rarer early- to mid-evening maximum, with the other three seasons tending towards diurnal quiescence, and (6) seasonally fluctuating (weak to strong) LE- 
EM and MLA peaks occur over South America. These diurnal maxima always occur during Spring -- except for the central-west Pacific where its springtime diurnal maximum has begun propagating to the east in response to the development of the $1998 \mathrm{El} \mathrm{Niño} \mathrm{(see} \mathrm{Bell} \mathrm{et} \mathrm{al.} \mathrm{1999).}$ The Atlantic ocean exhibits its own unique diurnal behavior. Here, weak LE-EM maxima occur during Spring and Summer, as well as the previously discussed delayed morning maxima which appear in Summer and Autumn. During wintertime, however, the Atlantic is diurnally quiet. Over Africa, it is evident that for the Winter season there are both prominent LE-EM and MLA rainfall peaks, but they also occur during the other three seasons -- noting the afternoon maximum is sometimes delayed to early- or mid-evening.

As discussed in the previous section, most of the accentuated regional diurnal behavior is coupled with the intensity of the associated rainfall. The largest LE-EM peak in the Indian ocean occurs in the Summer when the monsoon produces annual maxima over the central and northern basins. Rainfall over portions of the Pacific ocean are intermittently weak in the tropical zone (e.g., the central-west and central-east domains), and often over the sub-tropical zones. In such cases, the related afternoon peaks virtually always disappear. Throughout the Spring to Autumn period (either boreal or austral) when solar insolation is strong, the MLA maxima over land areas become strong and readily evident. [A pronounced early evening peak also occurs over the Indian ocean during Summer, a feature associated with the heavy summertime monsoon rains.] LE-EM peaks almost always persist along the equatorial trough in the Pacific ocean where ITCZ and SPCZ rainfall are the key features, however, it is only in confined regions highlighted by the central-west tropical Pacific (noted by Augustine 1984 in cloudiness data retrieved from geosatellite measurements) where the occasional prominent and sustained MLA maxima appear.

Figures 11a-b present a similar analysis to that shown in Fig. 10, but in this case calculated in a seasonal diurnal-latitude cross-section framework for rainfall averaged over the $50^{\circ}-110^{\circ} \mathrm{E}$ and $150^{\circ} \mathrm{E}-150^{\circ} \mathrm{W}$ sectors (similar to the sectors defined in Figs. 8a-b). [These results are also derived from the 2 a12 algorithm.] Over the Indian ocean sector (Fig 11a), a broad and strong LE-EM maximum is found throughout the four seasons, along with an indication of a delayed morning peak in Spring and Summer. There is also a broad but weaker LE-EM maximum in the Southern Hemisphere sub-tropics occurring south of $20^{\circ} \mathrm{S}$ during Winter and Spring, prior to the onset of the southwest monsoon. Moreover (as noted in the previous paragraph), there is a relatively strong Northern Hemisphere sub-tropical MLA maximum in 
Summer when the heavy rainfall region extends to $35^{\circ} \mathrm{N}$ due to the penetration of the SouthwestEast Asian monsoon -- but only a weak feature in Spring. Clearly, as Indian ocean rainfall propagates from $7^{\circ}$ to $35^{\circ}$ latitude during the progression from Winter to Summer, it carries with it a pronounced LE-EM diurnal mode.

The Indian ocean sector primary modes are also evident during Autumn, except for the diurnal behavior disappearing from higher latitudes as the summer monsoon withdraws. [The relatively greater rainfall accumulations in the morning and afternoon beyond $25^{\circ} \mathrm{N}$ are related to mid-latitude storm systems.] An identical analysis to what has been presented in Fig. 11a, except for a smaller region focusing on the strongest monsoon activity (not shown), was also conducted to verify the above features. These results reproduce the main features of Fig 11a, except for indicating even larger LE-EM amplitudes associated with the intense monsoon rainfall.

Over the central Pacific ocean sector (Fig. 11b) during Winter, the heaviest rainfall zone is between $25^{\circ} \mathrm{S}-10^{\circ} \mathrm{N}$, concentrated around $7^{\circ} \mathrm{S}$ and coincident with two distinct LE-EM and MLA peaks. Because of the northward movement of the ITCZ from its Winter position in the southern hemisphere to its Summer position in the northern hemisphere, the band of heavy rainfall in the central Pacific at approximately $7^{\circ} \mathrm{S}$ during Winter evolves into two heavy rainfall bands in Summer and Autumn -- around $7^{\circ} \mathrm{N}$ associated with the Summer ITCZ and around $7^{\circ} \mathrm{S}$ associated with the SPCZ. Another rainfall area north of $20^{\circ} \mathrm{N}$ indicates a single MLA peak around $35^{\circ} \mathrm{N}$, suggesting interactions with mid-latitude systems. Similar features are seen in the tropics during Spring, except that the MLA peak is delayed until early-evening. During Summer and Autumn, there are weak LE-EM maxima at around $7^{\circ} \mathrm{S}, 7^{\circ} \mathrm{N}$, and $20^{\circ} \mathrm{N}$. It should be noted that the breadths of the summertime northern and southern rain band maxima are different. This difference reflects variants in the activation and timing of the principle mechanism(s) producing the LE-EM maxima in the ITCZ and SPCZ rain systems, but does not represent any basic departure from the behavior of the coherent and primary LE-EM oceanic mode.

A further notable feature seen in both Figs. 11a-b is that the LE-EM rainfall peaks occur a few hours earlier in the heavy rainfall areas than in the surrounding areas. For example, the peak at the center of the wintertime mid-Pacific rainfall maximum is in the interval from 03-06 MST (LE) while the peaking in the surrounding areas takes place in the interval 06-09 MST (EM), i.e., a longer delay. Similar features are evident in the monthly analysis given in Fig 4 . These results, perhaps prone to an alternate interpretations, are consistent with the ideas of Gray 
and Jacobson (1977) who maintained that the day-night oceanic cycle of radiative forcing and incloud convergence between deep convection and its surroundings (i.e., the DRC interaction), is responsible for underlying LE-EM rainfall peaks within the mid-Pacific, and presumably in which the deepest convection would be the quickest to initiate the interaction.

The regional results extracted from Figs 10 and 11a-b are summarized in Figure 12 to help differentiate diurnal rainfall variability over the tropical Indian ocean $\left(15^{\circ} \mathrm{S}-15^{\circ} \mathrm{N}, 50\right.$ $\left.110^{\circ} \mathrm{E}\right)$ and tropical mid-Pacific ocean $\left(15^{\circ} \mathrm{S}-15^{\circ} \mathrm{N}, 150^{\circ} \mathrm{E}-150^{\circ} \mathrm{W}\right)$. Over the Indian ocean, the

primary LE-EM maximum is persistent, appearing within its notional time-frame during Summer, Autumn, and Winter, but delayed to late-morning (09-12 MST) during Spring. The secondary MLA oceanic peak appears unequivocally during Spring and Summer, but is not evident in Autumn and Winter. For the mid-Pacific ocean, the primary LE-EM peak persists all four seasons, while the secondary MLA peak is evident only for the Spring and Winter seasons.

\subsection{Amplitude-phase interpretation at seasonal scale}

Similar to what was done to produce Figs. 5a-b, amplitude-phase analysis is applied to the seasonal rainfall averages so that spatial distributions of diurnal rainfall properties can be inspected systematically. Figures $13 \mathrm{a}-\mathrm{b}$ present the amplitude distributions for Winter and Summer. The amplitude distributions for Winter obtained from the 2a12, 2a25, and $2 \mathrm{~b} 31$ algorithms are similar with respect to both general and specific features.(Fig. 13a). Strong diurnal activity is observed within the major ITCZ and SPCZ oceanic convergence zones and over the South American and African continents -- as well as their surrounding areas. Maxima are located over Indonesia, the central-east Pacific ocean, the eastern Indian ocean, South America, and western-equatorial Africa. Another active area is located within the extra-tropical Pacific where most rainfall emanates from mid-latitude baroclinic storm systems and their interactions with tropical waves (Chang et al. 2002).

During Summer (Fig. 13b), peak rainfall amplitudes propagate northward with maxima located in the northern Bay of Bengal, the southeastern China Sea, the Japanese archipelago, the eastern coastal Pacific, as well as north Africa and the eastern United States. The strong diurnal activity over the northern Bay of Bengal and South China Sea is related to the Southwest-East Asian summer monsoon. The strong maximum over Japan is related the Baiyu monsoon trough.

Comparison of Fig. 5a with Figs. 13a-b indicate that the seasonal amplitude distributions from the three algorithms are more consistent than found with monthly rainfall, whose spatial 
correlations were high to begin with (see Table 2). This simply denotes that the additional sampling gained by extending the averaging period by a factor of three helps reduce statistical noise. Furthermore, the results from Figs. 13a-b confirm that strong diurnal rainfall variability is most closely related to heavy rainfall systems, systems which undergo major seasonal variations in their locations but only minor variations in their diurnal characteristics.

Figures $14 a-b$ illustrate the associated phase distributions of the rainfall diurnal cycle for the Winter and Summer seasons. The related amplitudes of 15, 30, and $45 \mathrm{~mm}$ are indicated with shading, recalling that the phase distributions indicate times of peak rainfall for the 1st diurnal harmonic contributing to the total rainfall diurnal cycle. [Note that for both figures, the phase distribution patterns from the three algorithms are in qualitative agreement.] The heterogeneity of phase is evident in these diagrams, but as noted with the Fig. 2 result, most ocean areas indicate distinct LE-EM maxima and most continental areas indicate distinct MLA maxima. Clearly, in Winter, the high amplitude ocean regions are dominated by the LE-EM mode, particularly over the ITCZ and SPCZ convergence zones where diurnal amplitudes are at their peak values. Nevertheless, afternoon phase peaks are found over the tropical central-west Pacific and east Pacific in the more moderate amplitude regions, early afternoon phase peaks are apparent over the mid-latitude storm track regions in both hemispheres, and an evening phase peak occurs over the South China Sea. Conversely, the MLA mode dominates the high amplitude continental regions of Africa and South America.

Different phase patterns materialize for the Summer (Fig. 14b). A LE-EM maximum extends over most of the Pacific and Atlantic oceans, while a early afternoon maximum dominates the north Indian ocean. In addition, LE-EM maxima are apparent over the Bay of Bengal and the inland Indian monsoon region, while an early afternoon phase peak persists within the strong amplitude region over the South China Sea. A MLA phase peak is found over Africa as well as the Americas. Finally, there are early afternoon maxima over the coastal areas of China (perhaps from GWPC), coincident with late-morning and early-afternoon phase peaks within the mainland. This denotes that diurnal rainfall variability over southern China, whose central-southern eastern zone is frequented by summertime, mesoscale convective systems propagating off the Tibetan Plateau, is typically heterogeneous during its convection season. 


\subsection{Closing discussion on seasonal scale analyses}

Synthesis of the results presented in this section support the argument that diurnal rainfall variations are significant in both tropical and subtropical land and ocean areas, especially over heavy oceanic rainfall regions such as within the ITCZ, SPCZ, and Asian monsoon and the continental rainforest zone. Moreover, these results emphasize the dominance and perseverance of the two primary modes and presence of the two secondary modes. Although the exact timings of rainfall maxima vary from place-to-place and from season-to-season, and with a few notable exceptions such as the delayed early morning primary mode of the eastern tropical Atlantic and Indian oceans during Spring and Summer, and the delayed MLA mode to early- or mid-evening occurring intermittently over Africa and Scuth America (delayed primary) and selected portions of the Pacific ocean (delayed secondary), the coherent primary and secondary modes that have been described explain most diurnal variability that takes place in a time-averaged framework -particularly at the seasonal scale. Therefore, the two-each primary and secondary modes define the mainstream behavior of diurnal rainfall variability.

\subsection{Discussion and Conclusions}

Rainfall retrievals from the three level 2 TRMM ștandard algorithms have been analyzed in a diurnal framework for developing a better understanding of the nature of diurnal rainfall variability, the space-time distribution of the various diurnal modes of variability, and the mechanisms producing the various modes. One year of TMI and PR data from 1998 have been used in conjunction with TRMM level 2 algorithms $2 \mathrm{a} 12,2 \mathrm{a} 25$, and $2 \mathrm{~b} 31$ to conduct the study. Testing for repeatability amongst multiple algorithms is a means to help confirm the reliability of each of the individual algorithms, and given the consistent results produced by the three algorithms, it is concluded that the analyses presented in this investigation are sound. It is evident that the detailed diurnal properties of rainfall variability are more consistent between $2 \mathrm{a} 25$ and $2 \mathrm{~b} 31$ (the narrow-swath PR-only and TMI-PR Combined algorithms) than either is with 2 a 12 (the wide swath TMI-only algorithm), which is expected since $2 \mathrm{a} 12$ provides three times the sampling coverage than the two narrow-swath algorithms. However, for monthlycomposited analyses, even on a 3-hourly basis, these differences are minor insofar as the salient properties of diurnal rainfall variability. On a seasonal basis, the individual algorithm results are in even closer agreement, demonstrating that the less than $1 / 3^{\text {rd }}$ sampling capacity of the narrow- 
swath PR (relative to the wide-swath TMI) does not produce significant under-sampling insofar as quantifying the pattern of diurnal rainfall variability and its evolution.

From a general perspective, the investigation has shown that diurnal rainfall variability is a heterogeneous variable over both continents and ocean, but that within these two distinct heterogeneous patterns are both large and small scale coherent patterns, and most importantly -dominant features in amplitude and phase properties. First, there are more areas over continents with greater rainfall during daytime than nighttime, by a wide margin -- and conversely, more areas over oceans with greater rainfall during nighttime than daytime, by an even wider margin. Moreover, most continental daytime variability exhibits the MLA (15-18 MST) maximum, while most oceanic nighttime variability exhibits the LE-EM maximum (3-9 MST). There are obvious departures from this behavior, but most phase departures from these two primary modes can be described as "opposed secondary modes", i.e., for continents a secondary LE-EM maximum, and for oceans, a secondary MLA maximum. In essence, these are the overriding properties of diurnal rainfall variability in the tropics and subtropics.

Our results depart from a claim recently reported by Nesbitt and Zipser (2003), who examined the diurnal nature of the frequency of occurrence of MCS-type precipitation features indexed from TRMM TMI and PR measurements. One of their main conclusions, drawn from the method they used in conducting the study, was that diumal rainfall variability over the ocean is weak. We do not find this to be the case when examining rainfall itself, which Nesbitt and Zipser (2003) did not do. It should be stated that this may not be a contradiction in results when the two methodologies are examined in detail, although it will certainly be perceived as one.

Within this fabric of primary and secondary modes are several notable regional phenomena and several more instances where there are clear-cut regional departures from either the primary or secondary mode behavior. Of great interest is that diurnal rainfall variability is most prominent over heavy rainfall areas, particularly large scale convergence zones (highlighted by the ITCZ and SPCZ, and most of their V-sector intersection), monsoon regions, and storm tracks. For example, the V-sector where the ITCZ and SPCZ intersect and produce what could be described as a super-convection zone, is also where the largest diurnal precipitation amplitudes are found. Along this same line, the annual migrations of the ITCZ and SPCZ convergence zones produce coherent signals in diumal rainfall. Thus, in general, the amplitude distribution of the diumal rainfall cycle mimics that of the distribution of rainfall intensity -- the 
salient question being, is this a required relationship emanating from Gaussian statistics, or does intense rainfall carry within its hydrodynamic-thermodynamic makeup, distinct mechanisms (such as SRC, SRCM, and DRC interactions) for producing diurnal variations that are not present in less intense rainfall systems.

Another example of this phenomenon is how diurnal rainfall variability over the Indian ocean follows the onset, northward propagation, and withdrawal of the summertime SouthwestEast Asian monsoon. Also, the pattern of diurnal rainfall variability over the central Pacific ocean responds to the development and withdrawal of the 1997-98 El Niño event. All such examples favor an argument that large scale precipitation systems containing heavy convection excite either a static or dynamic mode of diurnal rainfall variability -- or both. Moreover, the Figs. 1la-b results illustrating the gradual delay of the phase peaks away from the convection centers in the Indian and Pacific ocean sectors provide support to the argument that the DRC interaction mechanism prevails -- although this assertion must be treated cautiously.

Clearly, there are areas of heavy rainfall over both continents and oceans that do not exhibit a primary phase mode, e.g., the east Atlantic which exhibits a delayed early morning mode, or the central tropical Pacific that exhibits a distinct MLA mode. By the same token, there are various regional scale areas of heavy rainfall that do not exhibit meaningful diurnal variability such as the northern part of South Africa and the central east Pacific equatorial region. Moreover, there is at least one prominent rainfall case which exhibits weak rainfall but also contains highly coherent diurnal rainfall variations. This is the case of sub-tropical marine stratocumulus regions off the west coasts of North America, South America, central-north Africa, and Australia, which all exhibit daytime maxima. These processes could be due to the secondary mode, OSH mechanism touted by Sui et al. $(1997,1998)$. However, we suggest it is more likely related to how solar-driven turbulence and daytime convection embedded in the stratocumulus layers activate precipitation microphysics, while at the same time producing breakup and erosion. It is emphasized that the diurnal behavior of precipitation in large-scale marine stratocumulus fields deserves further study because much of the precipitation in these fields is drizzle below the detection limit of either the PR or the TMI, and because these fields are widespread and climatically relevant due to their ability to cool the atmosphere radiatively if the cover area grows in size. 
The pattern of the LSH-SBCF mechanism due to ocean-land transect differential heating appears over the west Australian and South African coasts during their summer seasons in sufficient strength to confirm the durability of that mechanism at the monthly scale. Moreover, without an alternative explanation, the relative frequency of secondary mode, coherent LE-EM diurnal peaks over continental areas, argues in favor of the SRCL mechanism. By the same token, no standout evidence of the LSCH mechanism appears over the rainforests of South America or Africa at the monthly or seasonal time scales -- although this does not mean that a strong and large scale convection zone cannot propagate a diurnally coherent divergence pattern (accompanied by rainfall), away from the convection center in the course of a few days to a week. Nonetheless, these results suggest that the LSCH diumal mechanism is not a first order climate phenomenon. The same can be said of the BLWO and SDTM mechanisms, in that no sustained processes mimicking these diurnal signals are evident in the analyses. There is evidence of the GWPC mechanism -- diurnal processes akin to this mechanism are found off: (1) the southeast coast of China in Summer, (2) the east coasts of both South Africa and the continental U.S. during Winter, and (3) the southwest coast of India during Summer.

In essence, diurnal variability over the Earth is heterogeneous but regionally coherent and due to multiple mechanisms competing for dominance. At no time in seeking to decipher the cause of diurnal signals can the elements of "time to fruition", "downstream propagation", "available moisture", and "radiative-dynamic interactions" be overlooked -- because all of these processes are physically related to diurnal variability of rainfall and all can underlie the specific amplitude and exact timing of a phase peak. Diurnal rainfall variability is not a simple process, and defies simple explanations. Observational analyses such as presented here cannot unravel all the underlying physics producing variations, but they can help quantify the strength of the variations, the phasing of the variations, the location of the variations, and the regional to large scale coherency of the variations. It remains for modeling studies to reproduce the complexities found in the observations, before this subject can be put to rest. This has been recently stressed by Dai and Trenberth (2004) who found that a modern global climate model (the NCAR CCSM2) could not adequately reproduce the host of diurnal processes that occur in the atmosphere. Until then, this topic deserves more attention insofar as using modeling studies to corroborate observed phenomena. 


\subsection{Acknowledgments}

The authors extend their appreciation to Dr. Erich Stocker and the staff at the TRMM Data Information System (TSDIS) of the NASA/Goddard Space Flight Center for their efforts in supporting the production and reprocessing of the TRMM level 2 precipitation datasets. This research has been supported by NASA TRMM and GWEC grants NAG5-4752 and NAG512064 , respectively. 


\subsection{References}

Ackerman, S.A, and S.K. Cox, 1981: GATE phase III mean synoptic-scale radiative convergence profiles. Mon. Wea. Rev., 109, 371-383.

Albright, M.D., E.E. Recker, R.J. Reed, and R. Dang, 1985: The diurnal variation of deep convection and inferred precipitation in the central tropical Pacific during January-February 1979. Mon. Wea. Rev., 113, 1663-1680.

Anderson, S.P., R.A. Weller, and R.B. Lukas, 1996: Surface buoyancy forcing and the mixed layer of the western Pacific warm pool: Observation and one-dimensional model results. $J$. Clim., 9, 3056-3085.

Augustine, J.A., 1984: The diumal variation of large-scale inferred rainfall over the tropical Pacific Ocean during 1979. Mon. Wea. Rev., 112, 1745-1751.

Bell, G.D., M.S. Halpert, C.F. Ropelewski, V.E. Kousky, A.V. Douglas, R.C. Schnell, and M.E. Gelman, 1999: Climate assessment for 1998. Bull. Amer. Meteorol. Soc., 80, S1-S48.

Benton, G.S., and M.S. Estoque, 1954: Water vapor transfer over the North American continent. J. Meteorol., 11, 462-477.

Betts, A.K., 1982: Saturation point analysis of moist convective overturning. J. Atmos. Sci., 39, 1484-1505.

Blackadar, A:K., 1957: Boundary layer wind maxima and their significance for the growth of nocturnal inversions. Bull. Amer. Meteor. Soc., 38, 283-290.

Bonner W.D., 1968: Climatology of the low-level jet. Mon. Wea. Rev., 96, 833-850.

Brier, G.W., and J. S. Simpson, 1969: Tropical cloudiness and precipitation related to pressure and tidal variations. Quart. J. Roy. Meteor. Soc., 95, 120-147.

Chang, A.T.C., L.S. Chiu, and G. Yang, 1995: Diurnal cycle of oceanic precipitation from SSM/I data. Mon. Wea. Rev., 123, 3371-3380.

Chang, E.K.M., S. Lee, and K.L. Swanson, 2002: Storm track dynamics. J. Clim., 15, 21632183.

Chen, S.S., and R.A. Houze, Jr., 1997: Diurnal variation and life-cycle of deep convective systems over the Pacific warm pool. Quart. J. Roy. Meteorol. Soc., 123, 357-388.

Ciesielski, P.E., W.H. Schuibert, and R.H. Johnson, 2001: Diurnal variability of the marine boundary layer during ASTEX. J. Atmos. Sci., 58, 2355-2376.

Dai, A., 2001: Global precipitation and thunderstorm frequencies. Part II: Diurnal variations. $J$. Clim. 14, 1112-1128.

Dai, A., and K.E. Trenberth, 2004: The diurnal cycle and its depiction in the Community Climate System Model. J. Clim., 17, 930-951. 
Duvel, J.P., and R.S. Kandel, 1985: Regional-scale diurnal variations of outgoing inferred radiation observed by METEOSAT. J. Clim. Appl. Meteor., 24, 335-349.

Emanuel, K., 1986: An air-sea interaction theory of tropical cyclones. Part I: Steady state maintenance. J. Atmos. Sci., 43, 584-604.

Emanuel, K., 1994: Atmospheric Convection. Oxford University Press, New York, 580 pp.

Ebert, E.E., and M.J. Manton, 1998: Performance of satellite rainfall estimation algorithms during TOGA COARE. J. Atmos. Sci., 55,1537-1557.

Faysash, D.A., and E.A. Smith, 2000: Simultaneous retrieval of diurnal to seasonal surface temperatures and emissivities over SGP ARM-CART site using GOES split window. $J$. Appl. Meteor., 39, 971-982.

Foltz, G.S., and W.M. Gray, 1979: Diurnal variations in the troposphere's energy balance. $J$. Atmos. Sci., 36, 1450-1466.

Fu, R., A.D. Del Genio, and W.B. Rossow, 1990: Behavior of deep convective clouds in the tropical Pacific from ISCCP radiances. J. Clim., 3, 1129-1152.

Garreaud, R.D., and J.M. Wallace, 1997: The diurnal march of convective cloudiness over the Americas. Mon. Wea. Rev., 125, 3157-3171.

Garreaud, R.D., and R. Muñoz, 2004: The diurnal cycle in circulation and cloudiness over the subtropical southeast Pacific. J. Clim., 17, 1699-1710.

Gray, W.M., and R.W. Jacobson, Jr., 1977: Diurnal variation of deep cumulus convection. Mon. Wea. Rev., 105, 1171-1188.

Haddad, Z.S., E.A. Smith, C.D. Kummerow, T. Iguchi, M.R. Farrar, S.L. Durden, M. Alves, and W.S. Olson, 1997: The TRMM 'Day-1' radar/radiometer combined rain-profiling algorithm. J. Meteor. Soc. Japan, 75, 799-809.

Hamilton, K., 1981: A note on the observed diurnal and semidiurnal rainfall variations. $J$. Geophys. Res., 86, 12122-12126.

Hann, J., 1901: Lehrbuch der Meteorologie (1st ed). Chr. Herm Tachnitz, Leipzig, 338-346.

Haurwitz, B., and A.D. Cowley, 1973: The diurnal and semidiurnal barometric oscillations, global distribution, and annual variation. Pure Appl. Geophys., 102, 193-222.

Hitschfeld, W., and J. Bordan, 1954: Errors inherent in the radar measurement of rainfall at attenuating wavelengths. J. Meteorol., 11, 58-67.

Holton, J.R., 1968: The diurnal boundary layer wind oscillation above sloping terrain. Tellus, 19, 199-205.

Hou, A.Y., S.Q. Zhang, A.M.. da Silva, and W.S. Olson, 2000: Improving assimilated global datasets using TMI rainfall and columnar moisture observations. J. Clim., 13, 4180-4195. 
Huffman, G.J., R.F. Adler, M. Morrissey, D.T. Bolvin, S. Curtis, R. Joyce, B. McGavock, and J. Susskind, 2001: Global precipitation at one-degree daily resolution from multi-satellite observations. J. Hydromet., 2, 36-50.

Iguchi, T., and R. Meneghini, 1994: Intercomparison of single-frequency methods for retrieving a vertical rain profile from airborne or spaceborne radar data. J. Atmos. Oceanic Tech., 11, 1507-1511.

Iguchi, T., T. Kozu, R. Meneghini, J. Awaka, and K. Okamoto, 2000: Rain-profiling algorithm for the TRMM precipitation radar. J. Appl. Meteor., 39, 2038-2052.

Imaoka, K., and R.W. Spencer, 2000: Diurnal variation of precipitation over the tropical oceans observed by TRMM/TMI combined with SSM/I. J Clim., 13, 4149-4158.

Janowiak, J.E., P.A. Arkin, and M. Morrissey, 1994: An examination of the diurnal cycle in oceanic tropical rainfall using satellite and in situ data. Mon. Wea. Rev., 122, 2296-2311.

Jones, C., L.M.V. Carvalho, R.W. Higgins, D.E. Waliser, and J.K.E. Schemm, 2004: Climatology of tropical intraseasonal convective anomalies: 1979-2002. J. Clim., 17, 523539.

Kousky, V.E., 1980: Diurnal rainfall variation in Northeast Brazil. Mon. Wea. Rev., 108, 488498.

Kraus, E.B., 1963: The diurnal precipitation change over the sea. J. Atmos. Sci., 20, 546-551.

Kummerow, C., W.S. Olson, and L. Giglio, 1996: A simplified scheme for obtaining precipitation and vertical hydrometeor profiles from passive microwave sensors. IEEE Trans. Geosci. Rem. Sens., 34, 1213-1232.

Kummerow, C., W. Barnes, T. Kozu, J. Shiue, and J. Simpson, 1998: The tropical rainfall measuring mission (TRMM) sensor package. J. Atmos. Oceanic Tech., 15, 809-817.

Kummerow, C., J. Simpson, O. Thiele, W. Barnes, A.T.C. Chang, E. Stocker, R.F. Adler, A. Hou, R. Kakar, F. Wentz, P. Ashcroft, T. Kozu, Y. Hong, K. Okamoto, T. Iguchi, H. Kuroiwa, E. Im, Z. Haddad, G. Huffman, B. Ferrier, W.S. Olson, E. Zipser, E.A. Smith, T.T. Wilheit, G. North, T. Krishnamurti, and K. Nakamura, 2000: The status of the Tropical Rainfall Measuring Mission (TRMM) after two years in orbit. J. Appl. Meteor., 39, 19651982.

Lavoie, R.L., 1963: Some Aspects of Meteorology of the Tropical Pacific Viewed from an Atoll. Rep. No. 27, Institute of Geophysics, Univ. of Hawaii, 76 pp.

Liebmann, B., and A. Gruber, 1988: The annual variation of the diurnal cycle of outgoing longwave radiation. Mon. Wea. Rev., 116, 1659-1670.

Lin, X., D.A. Randall, and L.D. Fowler, 2000: Diurnal variability of the hydrologic cycle and radiative fluxes: Comparisons between observations and a GCM. J Clim., 13, 4159-4179.

Lindzen, R., 1978: Effect of daily variations of cumulonimbus activity on the atmospheric semidiurnal tide. Mon. Wea. Rev., 106, 526-533. 
Liu, C., and M.W. Moncrieff, 1998: Diurnal variations in the troposphere's energy balance. $J$. Atmos. Sci., 55, 2329-2344.

Mapes, B.E., and R.A. Houze, Jr., 1993: Cloud clusters ansd superclusters over the oceanic warm pool. Mon. Wea. Rev., 121, 1398-1415.

Mapes, B.E., T.T. Warner, M. Xu, and A.J. Negri, 2003a: Diurnal patterns of rainfall in northwestern South America. Part I: Observations and context. Mon. Wea. Rev.,131,799-812.

Mapes, B.E., T.T. Warner, and M. Xu, 2003b: Diurnal patterns of rainfall in northwestern South America. Part III: Diurnal gravity waves and nocturnal convection offshore. Mon. Wea. Rev, $131,830-844$.

McBride, J.L., and W.M. Gray, 1980: Mass divergence in tropical weather systems. Part I: Diumal variation. Quart. J. Roy. Meteor. Soc., 106, 501-516.

McGarry, M.M., and R.J. Reed, 1978: Diurnal variations in convective activity and precipitation during P.hases II and III of GATE. Mon. Wea. Rev., 106, 101-113.

Meisner, B.N., and P.A. Arkin, 1987: Spatial and annual variations in the diurnal cycle of largescale tropical convective cloudiness and precipitation. Mon. Wea. Rev., 115, 2009-2032.

Meneghini, R., and T. Kozu, 1990: Spaceborne Weather Radar. Artech House, 199 pp.

Meneghini, R., T. Iguchi, T. Kozu, L. Liao, K. Okamoto, J. Jones, and J. Kwiatkowski, 2000: Use of the surface reference technique for path attenuation estimates from the TRMM Precipitation Radar. J. Appl. Meteor., 39, 2053-2070.

Murakami, M., 1983: Analysis of the deep convective activity over the western Pacific and Southeast Asia. Part 1: Diurnal cycle. J. Meteor. Soc. Japan., 61, 60-75:

Nakamura, K., K. Okamoto, T. Ihara, J. Awaka, J. Kozu, and T. Manabe, 1990: Conceptual design of rain radar for the Tropical Rainfall Measuring Mission. Int. J. Satellite Communication, 8, 257-268.

Nesbitt, S.W., and E.J. Zipser, 2003: The diurnal cycle of rainfall and convective intensity according to three years of TRMM measurements. J Clim., 16, 1456-1475.

Nitta, T., and S. Esbensen, 1974: Diurnal variations in the western Atlantic trades. J. Meteor. Soc. Jan., 52, 254-257.

Okamoto, K., (ed.), 1988: A feasibility study of rain radar for the Tropical Rainfall Measuring Mission. J. Communications Research Laboratory, 35, 109-208.

Oki, T., and K. Musiaki, 1994: Seasonal change of the diurnal cycle of precipitation over Japan and Malaysia. J. Appl. Meteor., 33, 1445-1463.

Pielke, R.A., 2002: Mesoscale Meteorological Modeling. Academic Press (2nd edition), San Diego, $676 \mathrm{pp}$.

Ramage, C.S., 1971: Monsoon Meteorology. Academic Press, 295 pp. 
Randall, D.A., Harshvardhan, and D.A. Dazlich, 1991: Diurnal variability of the hydrologic cycle in a general circulation model. J. Atmos. Sci., 48, 40-62.

Rasmusson, E.M., 1968: Atmospheric water vapor transport and the water balance of North America: Part II. Large-scale water balance investigations. Mon. Wea. Rev., 96, 720-734.

Ray, C.L., 1928: Diurnal variation of rainfall at San Juan, P.R. Mon. Wea. Rev., 56, 140-141.

Reed, R.J., and K.D. Jaffe, 1981: Diurnal variation of summer convection over West Africa and the tropical eastern Atlantic during 1974 and 1978. Mon. Wea. Rev., 109, 2527-2534.

Roll, H.U., 1965: Physical Climatology. Univ. of Chicago Press, 272 pp.

Rozendaal, M.A., C.B Leovy, and S.B. Klein,, 1995: An observational study of diurnal variations of marine stratiform cloud. J. Clim., 8, 1795-1809.

Rupprecht, E.; and W.M. Gray, 1976: Analysis of satellite-observed cloud clusters: Papers I and II. Tellus, 28, 391-425.

Sherwood, S.C., and R. Wahrlich, 1999: Observed evolution of tropical deep convective events and their environment. Mon. Wea. Rev., 127, 1777-1795.

Short, D.A., and J.M. Wallace, 1980: Satellite-inferred morning to evening cloudiness changes. Mon. Wea. Rev., 108, 1160-1169.

Short, D.A. and K. Nakamura, 2000: TRMM radar observations of shallow precipitation over the tropical oceans. J. Clim., 13, 4107-4124.

Silva Dias, P.L., J.P. Bonatti, and V.E. Kousky, 1987: Diurnally forced tropical tropospheric circulation over South America. Mon. Wea. Rev., 115, 1465-1478.

Simpson, J., C. Kummerow, W.-K. Tao, and R. Adler, 1996: On the Tropical Rainfall Measuring Mission (TRMM). Meteorol. Atmos. Phys., 60, 19-36.

Simpson, J., J. Halverson, H. Pierce, C. Morales, and T. Iguchi, 1998: Eyeing the eye: Exciting early stage science results from TRMM. Bull. Amer. Meteor. Soc., 79, 1711.

Smith, E.A., J. Turk, M. Farrar, A. Mugnai, and X. Xiang, 1997: Estimating $13.8 \mathrm{GHz}$ path integrated attenuation from $10.7 \mathrm{GHz}$ brightness temperatures for TRMM combined PR-TMI precipitation algorithm. J. Appl. Meteor., 36, 365-388.

Smith, E.A., J. Lamm, R. Adler, J. Alishouse, K. Aonashi, E. Barrett, P. Bauer, W. Berg, A. Chang, R. Ferraro, J. Ferriday, S. Goodman, N. Grody, C. Kidd, D. Kniveton, C. Kummerow, G. Liu, F. Marzano, A. Mugnai, W. Olson, G. Petty, A. Shibata, R. Spencer, F. Wentz, T. Wilheit, and E. Zipser, 1998: Results of WetNet PIP-2 project. J. Atmos. Sci., 55, 1483-1536.

Sui, C.-H., K.-M. Lau, Y.N. Takayabu, and D.A. Short, 1997: Diurnal variations in tropical oceanic cumulus convection during TOGA COARE. J. Atmos. Sci., 54, 639-655. 
Sui, C.-H., K.-M. Lau, and X. Li, 1998: Convective-radiative interaction in simulated diurnal variations of tropical cumulus ensemble. J. Atmos. Sci., 55, 2345-2357.

Tao, W.-K., C.-H. Sui, B. Ferrier, S. Lang, J. Scala, M.-D. Chou, and K. Pickering, 1993: Heating, moisture, and water budgets of tropical and midlatitude squall lines: Comparisons and sensitivity to longwave radiation. J. Atmos. Sci., 50, 673-690.

Tao, W.-K., S. Lang, J. Simpson, C.-H. Sui, B. Ferrier, and M.-D. Chou, 1996: Mechanisms of cloud-radiation interaction in the tropics and midlatitudes. J. Atmos. Sci., 53, 2624-2651.

Tao, W.-K., E.A. Smith, R. Adler, Z. Haddad, A. Hou, T. Iguchi, R. Kakar, T.N. Krishnamurti, C. Kummerow, S. Lang, R. Meneghini, K. Nakamura, T. Nakazawa, K. Okamoto, W. Olson, S. Satoh, S. Shige, J. Simpson, Y. Takayabu, G. Tripoli, and S. Yang, 2004: Latent heating from TRMM satellite measurements. Bull. Amer. Meteorol. Soc., submitted.

Trenberth, K.E., J.M. Caron, D.P. Stepaniak, and S. Worley, 2002: Evolution of El NiñoSouthern Oscillation and global atmospheric surface temperature. J. Geophy. Res., 107, 4065-4083.

Tripoli, G.J., 1992: An explicit three-dimensional nonhydrostatic simulation of a tropical cyclone. Meteorol. Atmos. Phys., 49, 229-254.

Turk, F.J., E.A. Smith, E. Amitai, E. Ebert, J. Hawkins, F.S. Marzano, A.Mehta, A. Mugnai, and B.J. Sohn, 2004: Blending coincident TRMM, SSM/I, and GEO-IR satellite data for rapid updates of global rainfall. Bull. Amer. Meteor. Soc., for submission.

Turton, J.D., and S. Nicholls, 1987: A study of the diurnal variations of stratocumulus using a multiple mixed layer model. Quart. J. Roy. Meteor. Soc.,113, 969-1009.

Vincent, D.G., 1994: The Southern Pacific Convergence Zone (SPCZ): A review. Mon. Wea. Rev., 122, 1949-1970.

Waliser, D.E., and C. Gautier, 1993: A satellite-derived climatology of ITCZ. J. Clim., 6, 21622174.

Wallace, J.M., and R.F. Todd, 1974: Some further results concerning the vertical structure of atmospheric tidal motions within the lowest 30 kilometers. Mon. Wea. Rev., 102, 795-803.

Wallace, J.M., 1975: Diurnal variations in precipitation and thunderstorm frequency over the conterminous United States. Mon. Wea. Rev., 103, 406-419.

Wallace, J.M., and P.V. Hobbs, 1977: Atmospheric Science: Introductory Survey. Academic Press, $457 \mathrm{pp}$.

Warner, T.T., R.E. Mapes, and M. Xu, 2003: Diurnal patterns of rainfall in northwestern South America. Part II: Model simulations. Mon. Wea. Rev., 131, 813-829.

Warren, S.G., C.J. Hahn, J. London, R.M. Chervin, and R.L. Jenne, 1986: Global Distribution of Total Cloud Cover and Cloud-type Amounts over Land. Technical Report NCAR/TN273+STR, National Center for Atmospheric Research, Boulder, CO, 29 pp. with 199 maps. 
Weller, R.A., and S.P. Anderson, 1996: Surface meteorology and air-sea fluxes in the western equatorial Pacific warm pool during TOGA Coupled Ocean-Atmosphere Response Experiment. J. Clim., 9, 1959-1990.

Wilheit, T., R. Adler, S. Avery, E. Barrett, P. Bauer, W. Berg, A. Chang, J. Ferriday, N. Grody, S. Goodman, C. Kidd, D. Kniveton, C. Kummerow, A. Mugnai, W. Olson, G. Petty, A. Shibata, E. Smith, and R. Spencer, 1994: Algorithms for the retrieval of rainfall from passive microwave measurements. Remote Sensing Rev., 11, 163-194.

$\mathrm{Xu}, \mathrm{K}$., and K.A. Emanuel, 1989: Is the tropical atmospherte conditionally unstable? Mon. Wea. Rev., 117, 1471-1479.

Yang, G.-Y., and J. Slingo, 2001: The diurnal cycle in the tropics. Mon. Wea. Rev., 129, 784 801.

Yang, S., and E.A. Smith, 1999: Four dimensional structure of monthly latent heating derived from SSM/I satellite measurements. J. Clim., 12, 1016-1037. 


\section{List of Tables}

Table 1: Summary of published mechanisms for explaining diurnal rainfall variability (not exhaustive).

Table 2: Correlations between diurnal rainfall variability amplitude and phase distribution quantities from TRMM algorithms 2a12, 2a25, and 2b31 for January and July, 1998. 


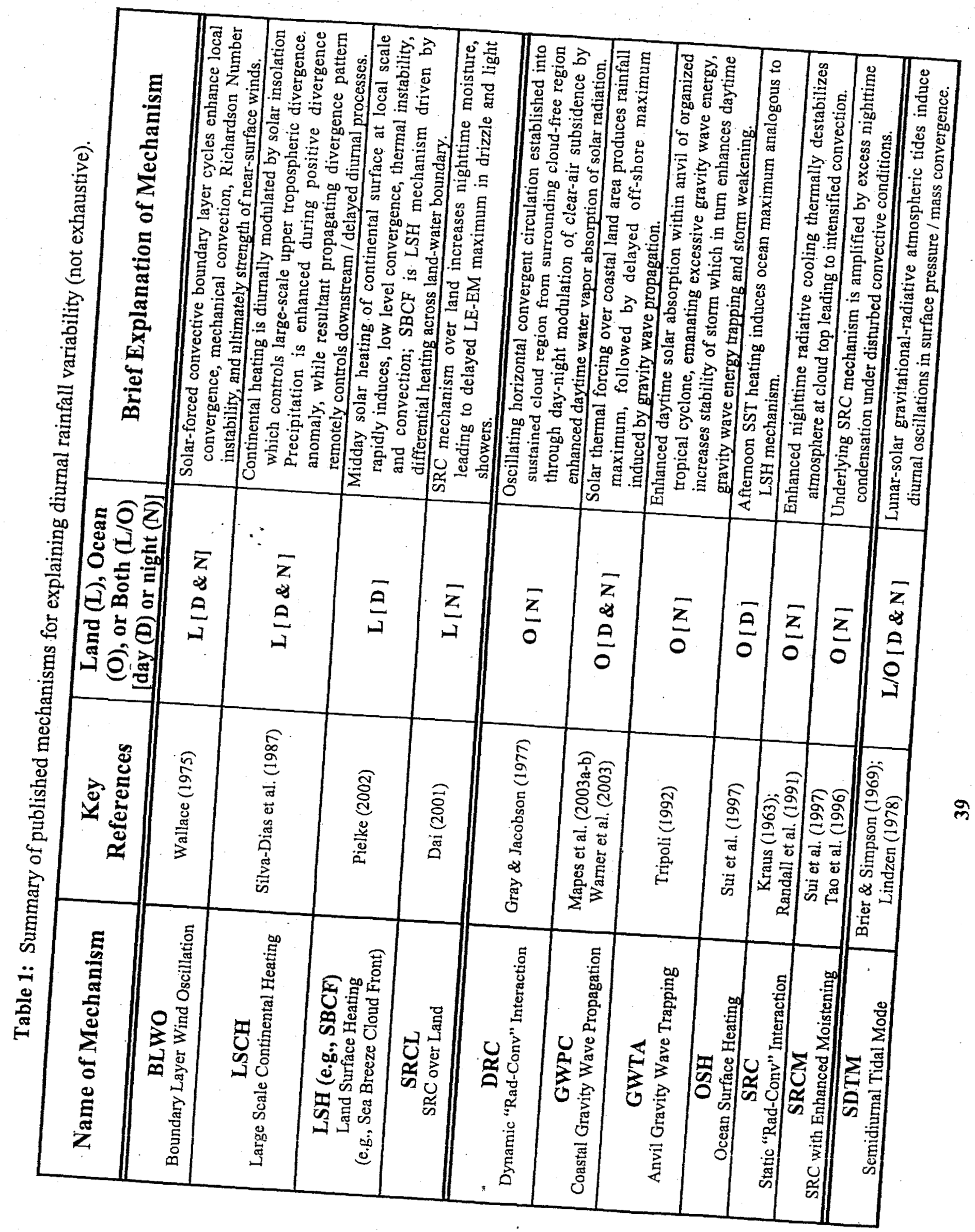


Table 2: Correlations between diurnal rainfall variability amplitude and phase distribution quantities from TRMM algorithms 2a12, 2a25, and 2b31 for January and July, 1998.

\begin{tabular}{|c|c|c|c|c|}
\cline { 2 - 5 } \multicolumn{1}{c|}{} & \multicolumn{2}{c|}{ Jan'98 } & \multicolumn{2}{c|}{ Jul'98 } \\
\cline { 2 - 5 } \multicolumn{1}{c|}{} & Amplitude & Phase & Amplitude & Phase \\
\hline 2a12-2a25 & 0.85 & 0.74 & 0.86 & 0.67 \\
\hline 2 a12 - 2b31 & 0.84 & 0.71 & 0.87 & 0.67 \\
\hline $2 \mathbf{a 2 5}-2 \mathbf{b 3 1}$ & 0.98 & 0.93 & 0.98 & 0.93 \\
\hline
\end{tabular}




\section{List of Figures}

Figure 1a: Distributions of daytime (0600-1800 MST) monthly rainfall accumulation over global tropics for Feb'98 produced by Version 6 2b31, 2a25, and 2a12 standard TRMM profile algorithms (upper, center, lower panels) -- color bar denotes mm accumulation.

Figure 1b: Same as Fig. la, except for nighttime (1800-0600 MST).

Figure 2: Ratio of daytime to nighttime monthly rainfall accumulations for TRMM algorithm 2 a25 (as given in Figs. 1ạ-b) -- gray scale denotes unitless ratio.

Figure 3a: Distributions of 3-hourly monthly rainfall accumulation (mm) over first four 3-hour periods of diurnal cycle for Jan'98 produced by 2al2 algorithm.

Figure 3b: Same as Fig.3a, except for last four 3-hour periods of diurnal cycle.

Figure 4: Diurnal-longitude cross-section of rainfall accumulation (mm) over $15^{\circ} \mathrm{S}-\mathrm{Eq}$ latitude zone for Jan'98 produced by 2a12 TRMM algorithm.

Figure 5a: Distributions of amplitude ( $\mathrm{mm}$ ) in diurnal rainfall variability for Jan'98 produced by $2 \mathrm{~b} 31,2 \mathrm{a} 25$, and 2a12 TRMM algorithms.

Figure 5b: Same as Fig. 5a, except for phase (MST at maximum of 1st diurnal Fourier harmonic) and just for $2 \mathrm{a} 12$ algorithm -- shaded areas indicate regions of largest amplitudes as shown in Fig. 5a.

Figure 6a: Diurnal-month cross-sections of 3-hourly, ocean-based rainfall accumulation (mm) over 1998 annual cycle produced by 2b31, 2a25, and 2a12 TRMM algorithms.

Figure 6b: Same as Fig. 6a, except for land-based rainfall accumulation. $\quad \because$

Figure 7a: Month-longitude cross-sections of amplitude ( $\mathrm{mm}$ ) and phase (MST at maximum of 1st diurnal Fourier harmonic) (left-hand and right-hand panels, respectively) of diurnal rainfall variability within $10^{\circ} \mathrm{S}-10^{\circ} \mathrm{N}$ latitude zone over 1998 annual cycle, produced by three level 2 TRMM algorithms. Top labels indicate: (1) African Continent (AF), Indian Ocean (IO), West-Central Pacific Ocean (W-CP), Easter Pacific Ocean (EP), South American Continent (SA), and Atlantic Ocean (AO), respectively. Date line shown with thick blue arrows; propagation paths shown with thin red arrows.

Figure 7b: Rainfall accumulation (mm) associated with Fig. 7a.

Figure 8a: Month-latitude cross-sections of amplitude $(\mathrm{mm})$ of diurnal rainfall variability for $50^{\circ}-110^{\circ} \mathrm{E}$ (upper panel) and $150^{\circ} \mathrm{E}-150^{\circ} \mathrm{W}$ (lower panel) longitude sectors over 1998 annual cycle produced by $2 \mathrm{a} 12$ TRMM algorithm.

Figure 8b: Same as Fig. 8a, except for phase (MST at maximum of 1st diurnal Fourier harmonic). 
Figure 9: Diurnal variation of seasonal rainfall accumulation (Winter, Spring, Summer, Autumn) averaged separately for land and ocean over TRMM observation zone $\left(35^{\circ} \mathrm{S}\right.$ to $35^{\circ} \mathrm{N}$ ) for 1998 annual cycie using $2 \mathrm{a} 12$ standard V5 TRMM profile algorithm. [See text for monthly assignments to seasons.]

Figure 10: Season-longitude cross-sections for four seasons of rainfall accumulation (mm) for $10^{\circ} \mathrm{S}-10^{\circ} \mathrm{N}$ latitude zone over 1998 annual cycle produced by $2 \mathrm{a} 12$ algorithm.

Figure 11a: Season-latitude cross-sections for four seasons of rainfall accumulation (mm) for $50^{\circ}-110^{\circ} \mathrm{E}$ longitude sector over 1998 annual cycle produced by 2a12 TRMM algorithm.

Figure 11b: Same as Fig 11a, except for $150^{\circ} \mathrm{E}-150^{\circ} \mathrm{W}$ longitude sector.

Figure 12: Diurnal-season cross-sections of rainfall accumulation $(\mathrm{mm})$ for region in Indian Ocean $\left(15^{\circ} \mathrm{S}-15^{\circ} \mathrm{N} / 50^{\circ}-110^{\circ} \mathrm{E}\right)$ (upper panel) and region in Pacific ocean $\left(15^{\circ} \mathrm{S}-15^{\circ} \mathrm{N} /\right.$ $150^{\circ} \mathrm{E}-150^{\circ} \mathrm{W}$ ) (lower panel) over 1998 annual cycle produced by $2 \mathrm{a} 12 \mathrm{TRMM}$ algorithm.

Figure 13a: Distributions of amplitude $(\mathrm{mm})$ of rainfall variability for Winter-1998 produced by $2 \mathrm{~b} 31,2 \mathrm{a} 25$, and 2a12 TRMM algorithms -- shaded areas indicate amplitudes of 15,30 , and $45 \mathrm{~mm}$, respectively.

Figure 13b: Same as Fig. 13a, except for Summer-1998 - shaded areas indicate regions of largest amplitude.

Figure 14a: Distributions of phase (MST at maximum of 1st diurnal Fourier harmonic) of rainfall variability for Winter-1998 produced by $2 \mathrm{~b} 31,2 \mathrm{a} 25$, and 2a12 TRMM algorithms -with shaded areas indicating regions of largest amplitudes as shown in Fig. 13a.

Figure 14b: Same as Fig. 14a, except for Summer-1998 -- shaded areas indicate regions of largest amplitudes. 

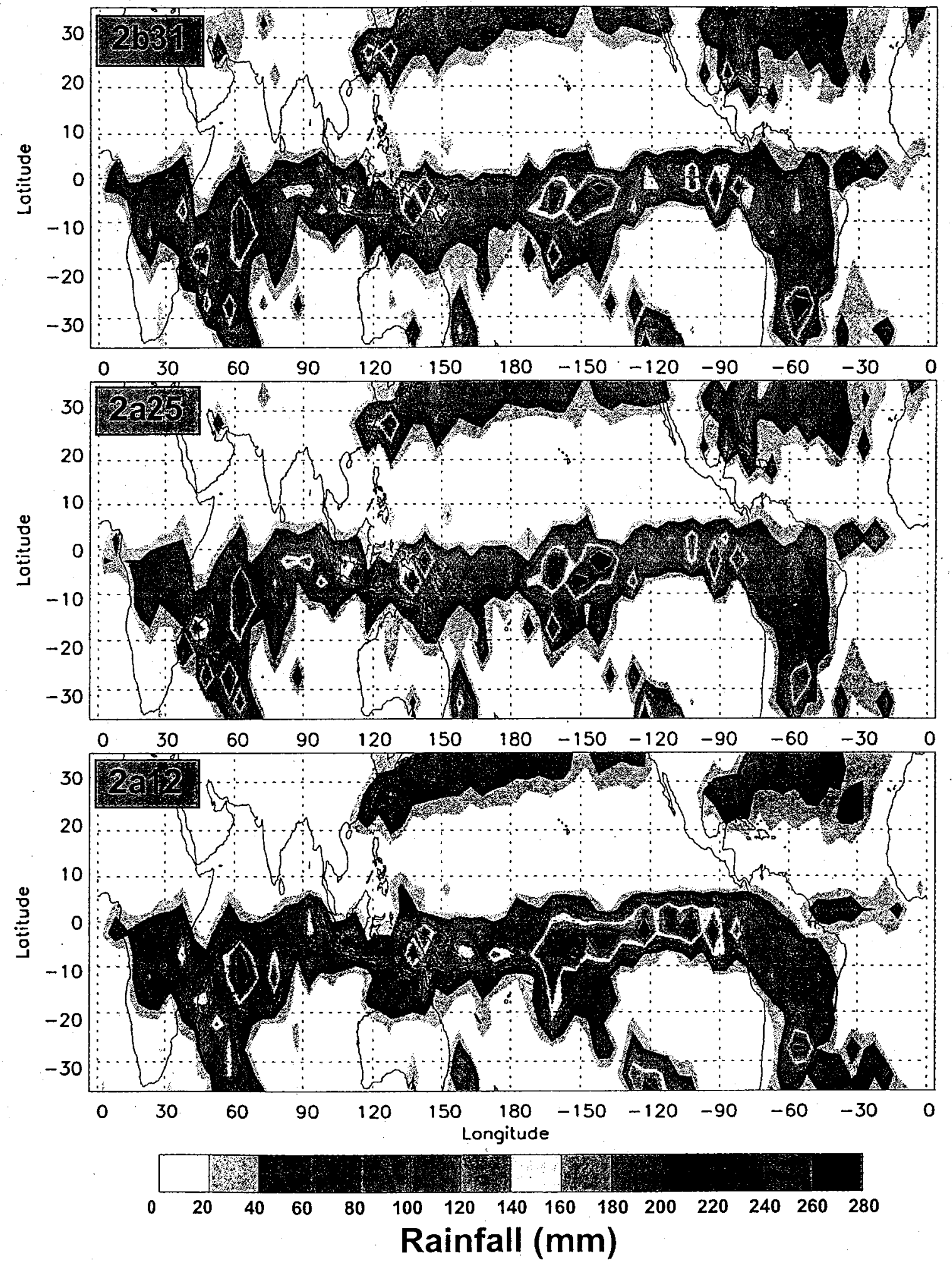

Figure 1a: Distributions of daytime (0600-1800 MST) monthly rainfall accumulation over global tropics for Feb'98 produced by Version 6 2b31, 2a25, and 2a12 standard TRMM profile algorithms (upper, center, lower panels) -- color bar denotes mm accumulation. 

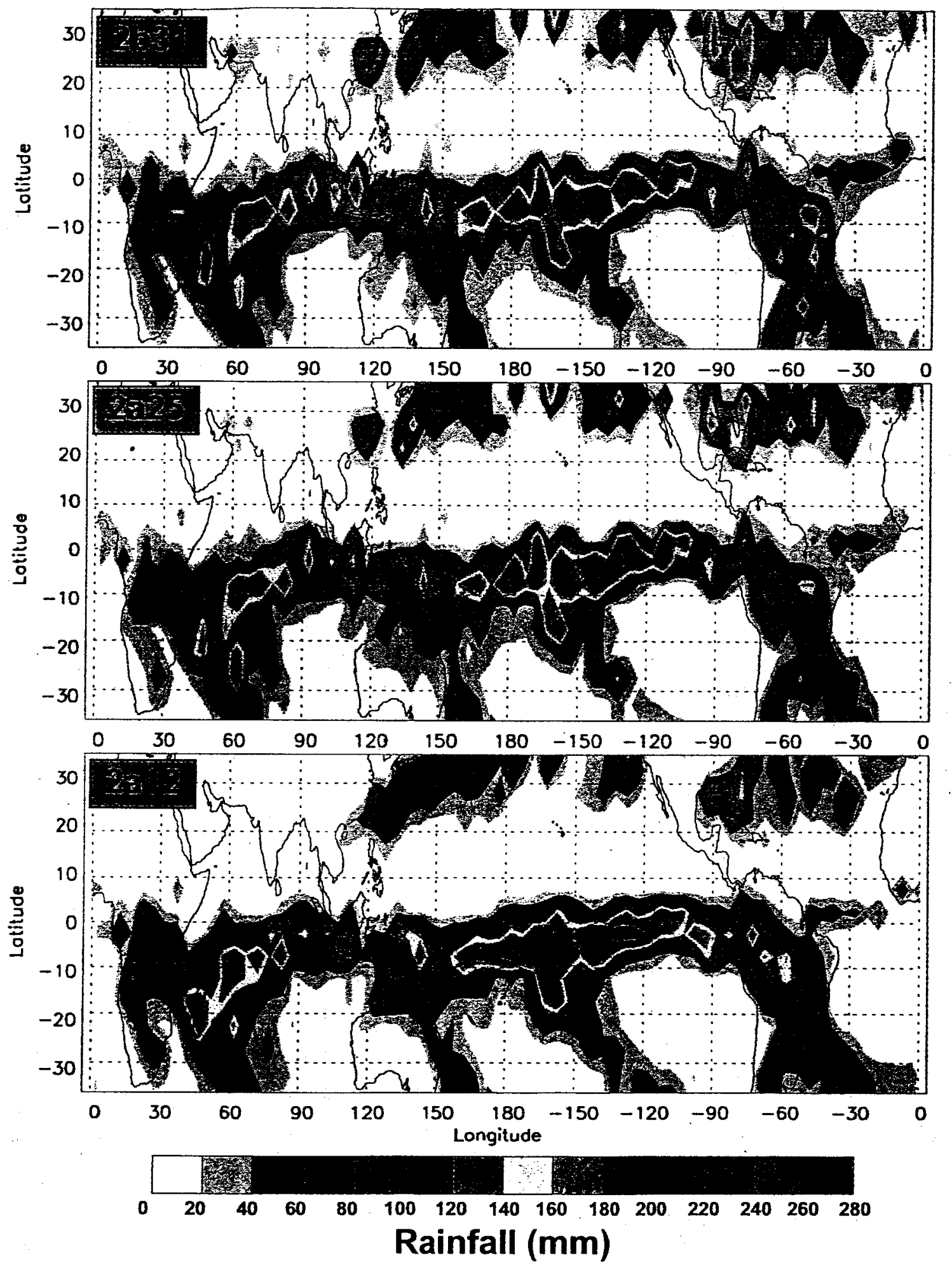

Figure 1b: Same as Fig. 1a, except for nighttime (1800-0600 MST). 


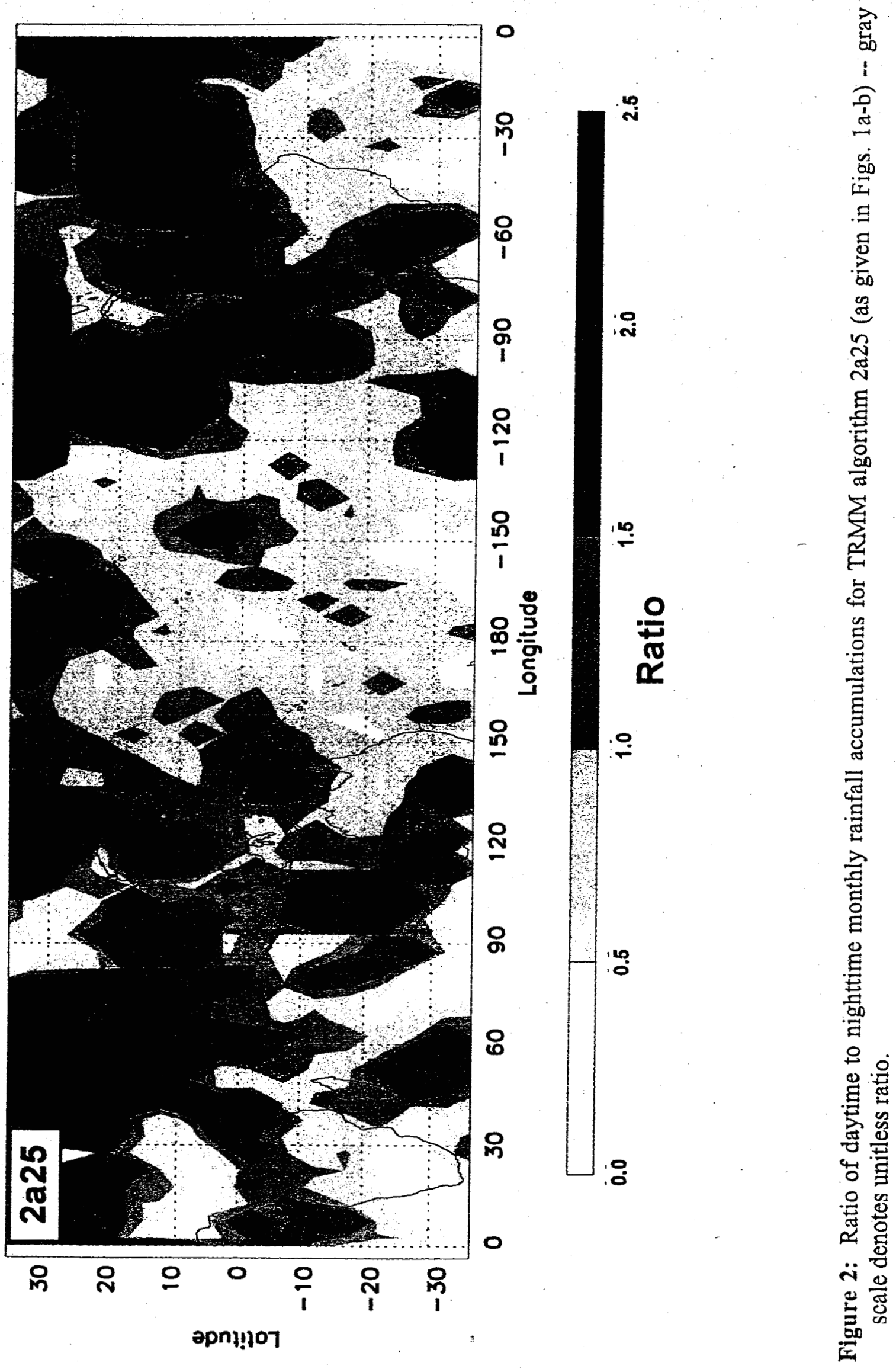




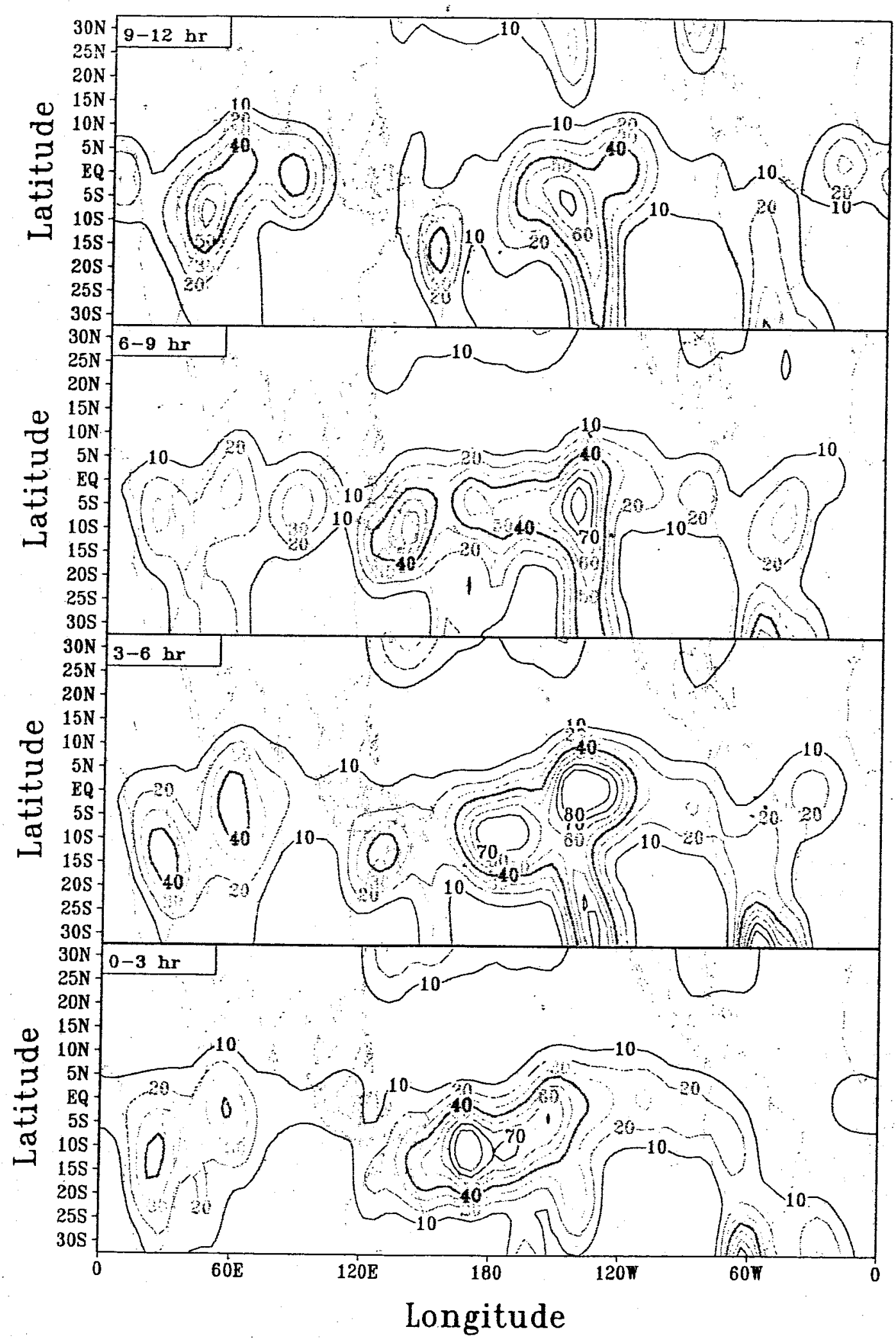

Figure 3a: Distributions of 3-hourly monthly rainfall accumulation (mm) over first four 3-hour periods of diurnal cycle for Jan'98 produced by $2 \mathrm{a} 12$ algorithm. 


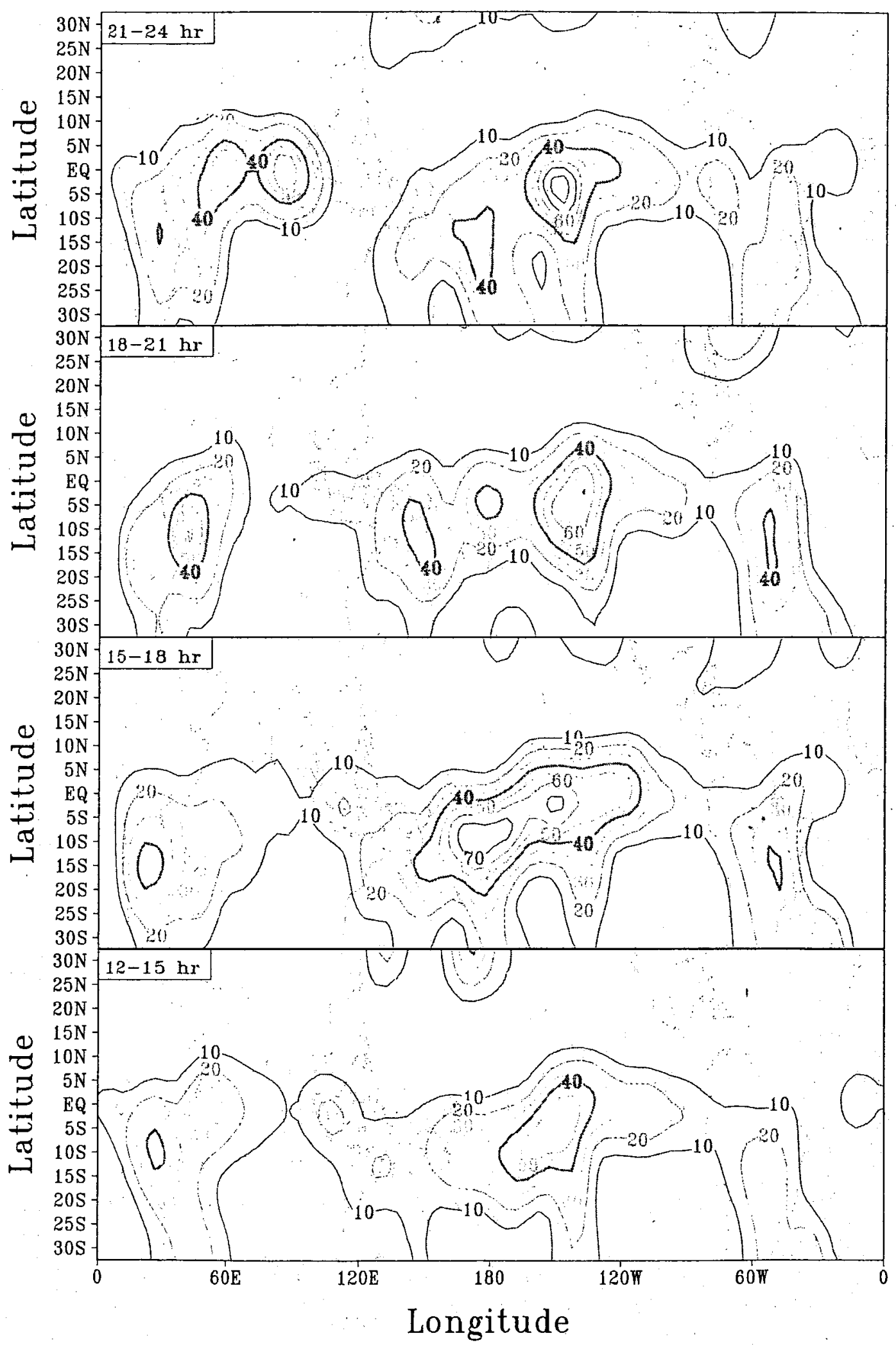

Figure 3b: Same as Fig.3a, except for last four 3-hour periods of diurnal cycle. 


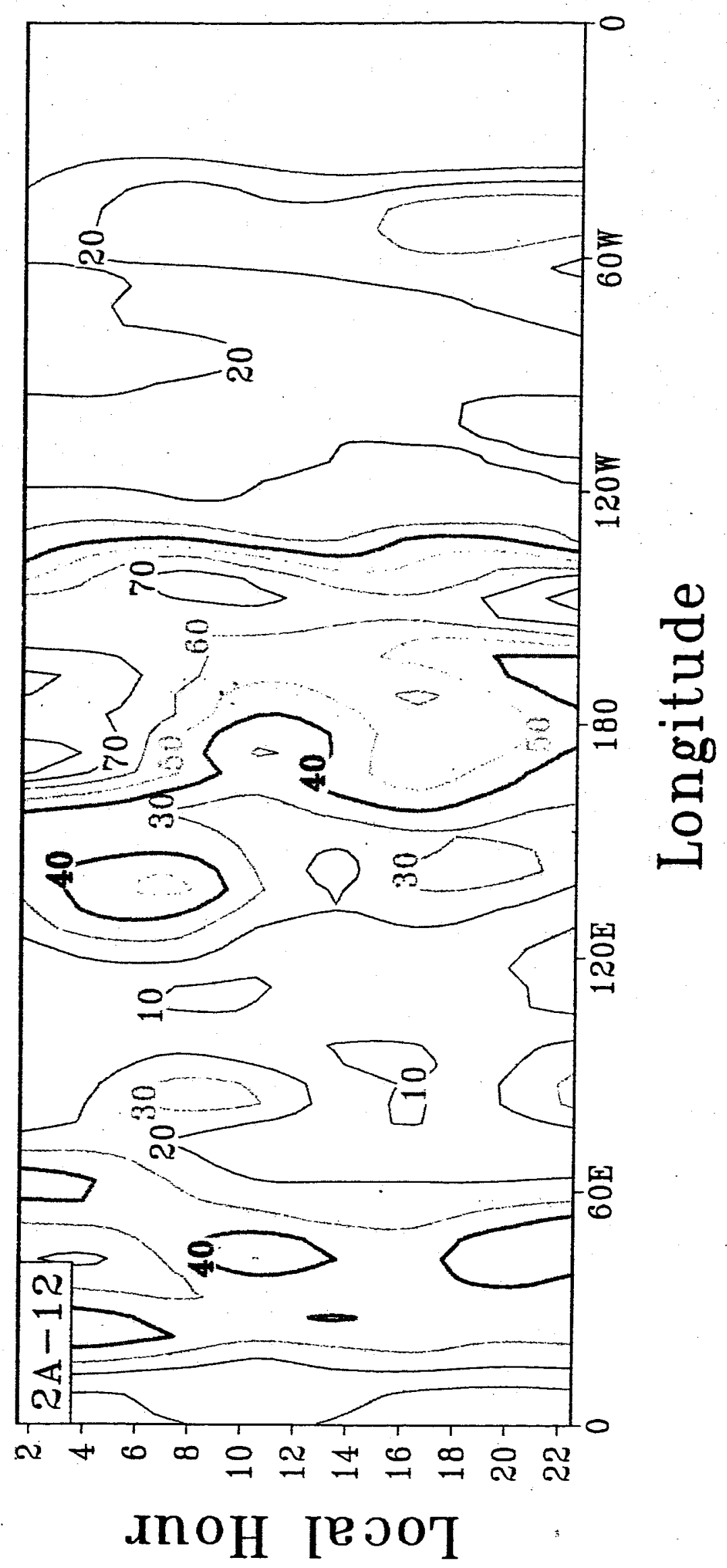

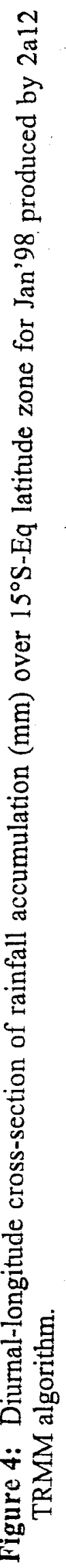




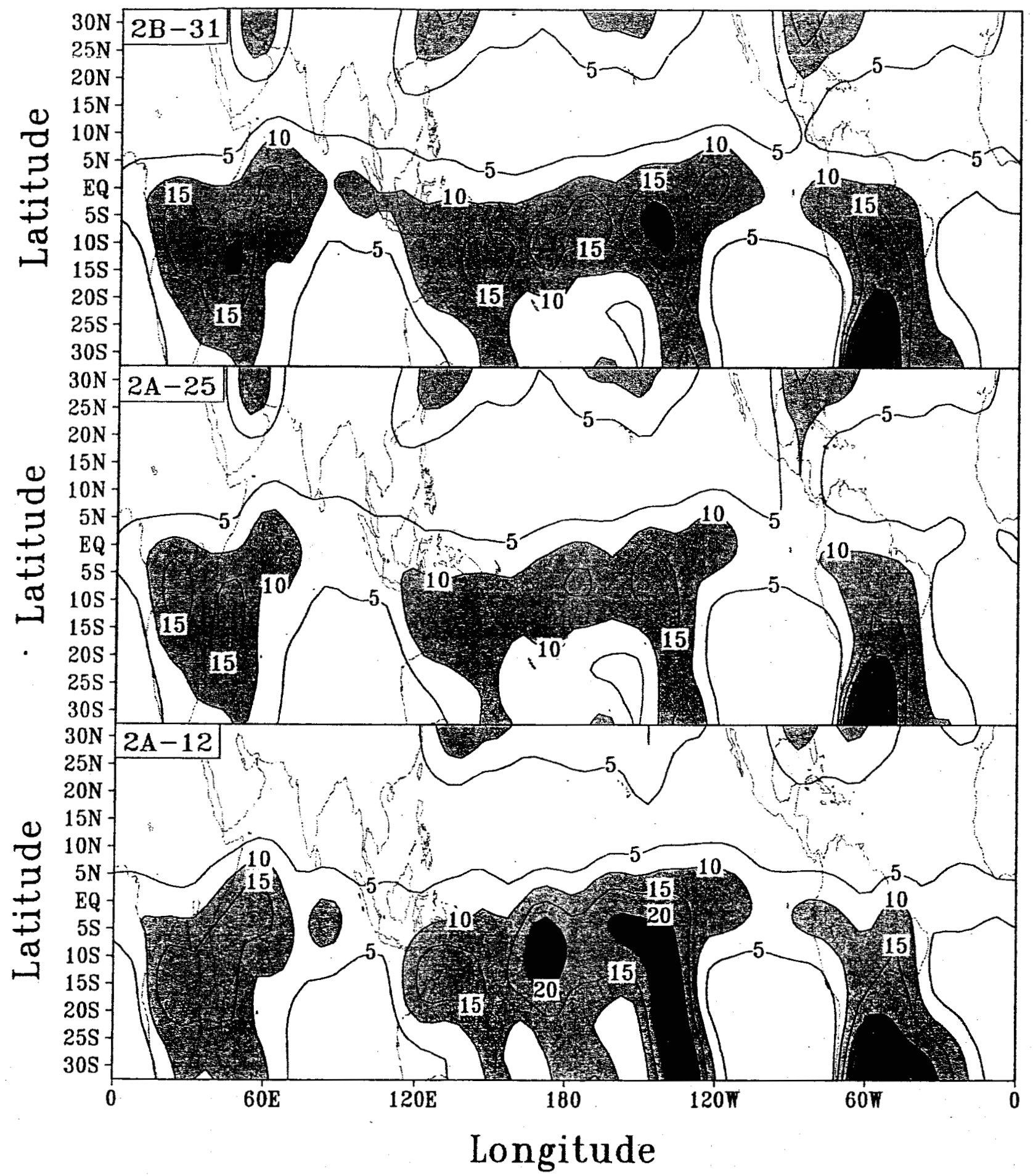

Figure 5a: Distributions of amplitude $(\mathrm{mm})$ in diurnal rainfall variability for Jan' 98 produced by $2 \mathrm{~b} 31,2 \mathrm{a} 25$, and 2a12 TRMM algorithms. 


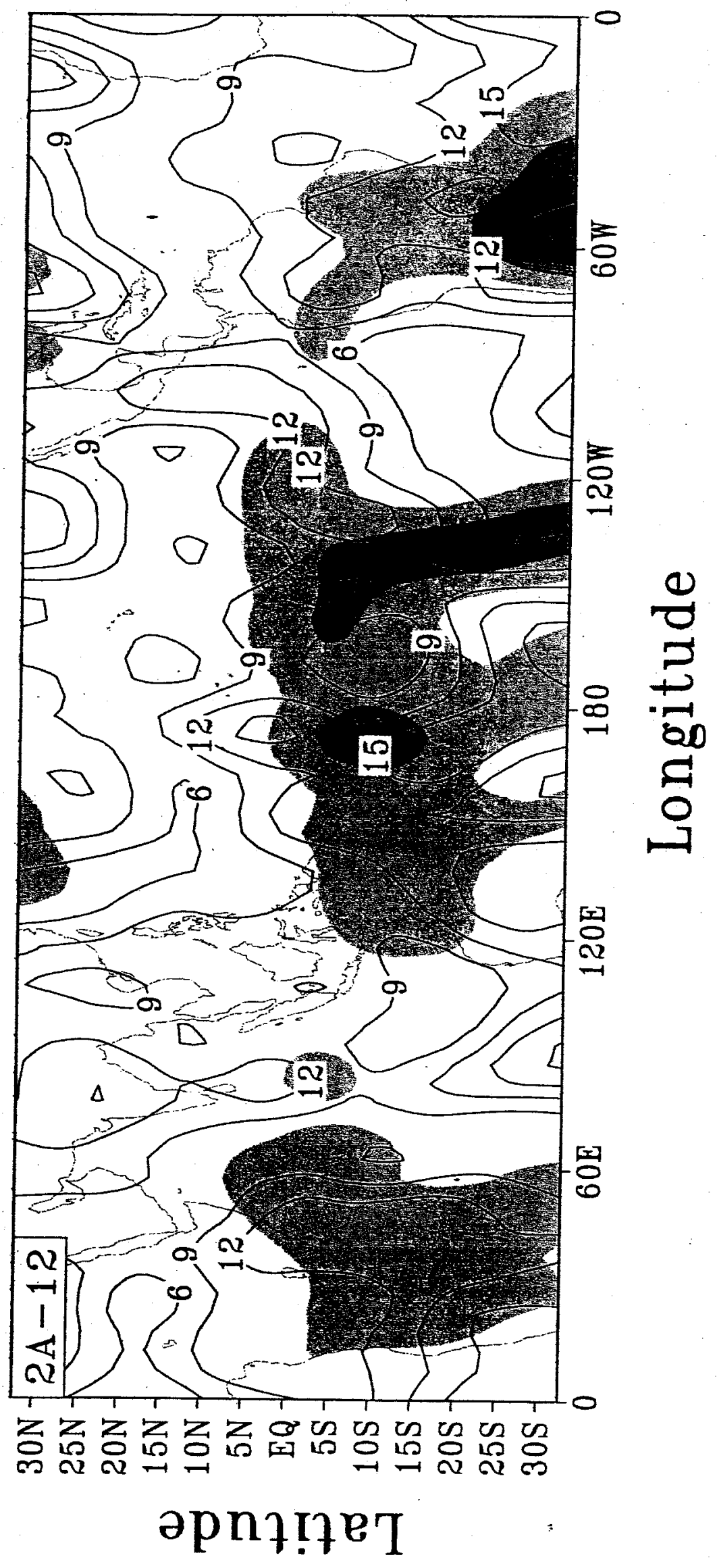

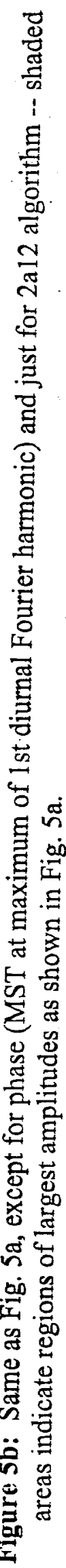



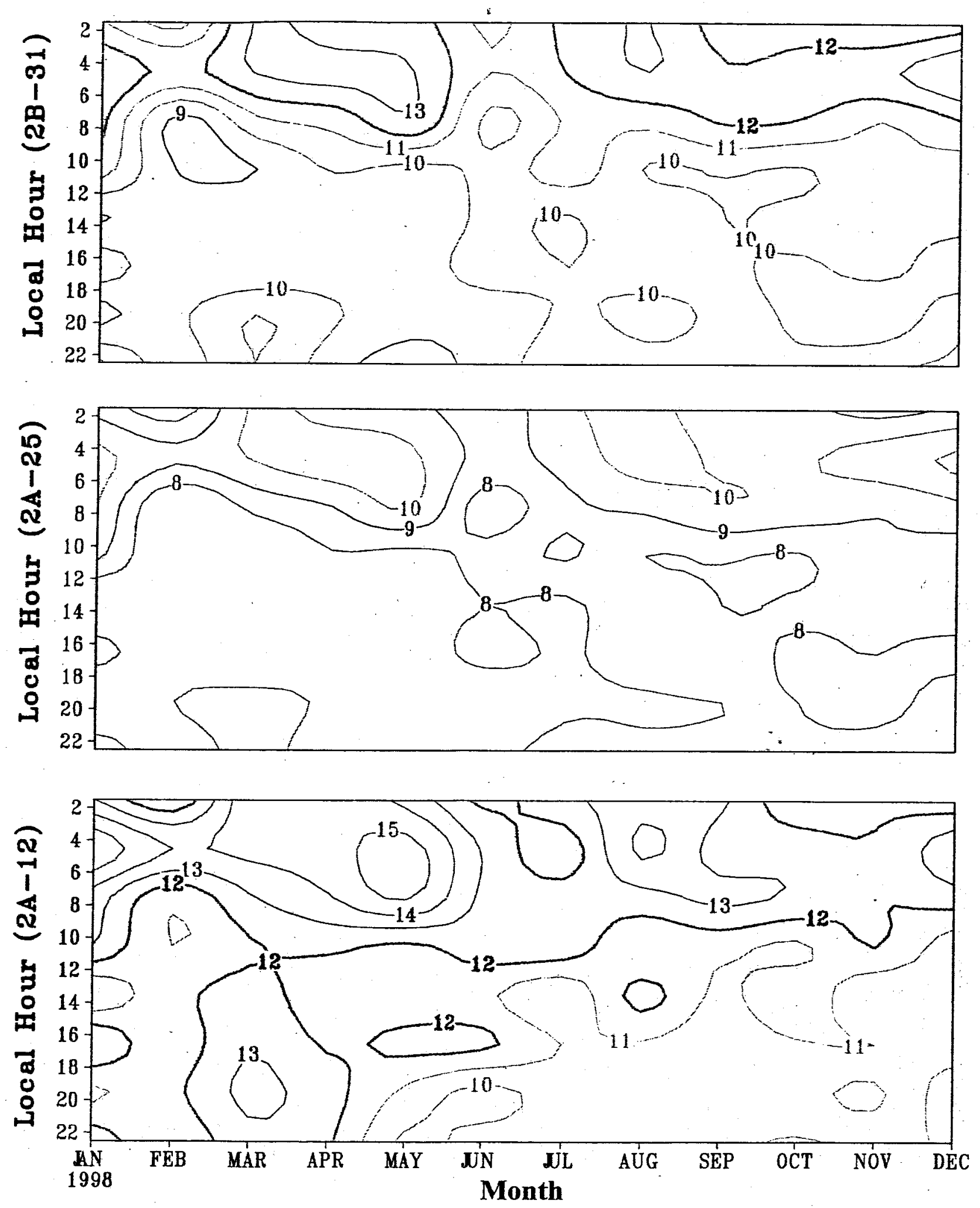

Figure 6a: Diurnal-month cross-sections of 3-hourly, ocean-based rainfall accumulation (mm) over 1998 annual cycle produced by 2b31,2a25, and 2a12 TRMM algorithms. 

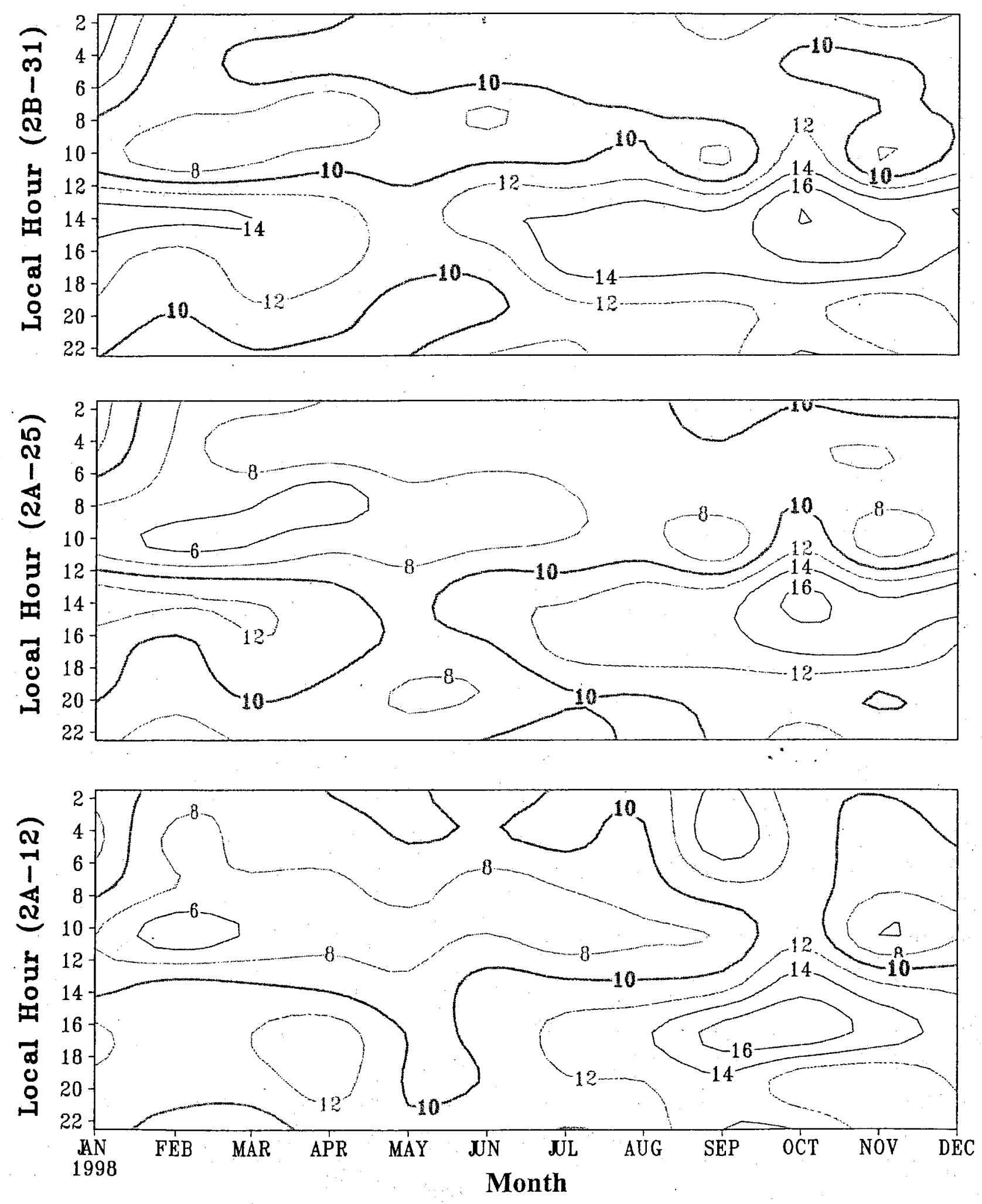

Figure 6b: Same as Fig. 6a, except for land-based rainfall accumulation. 


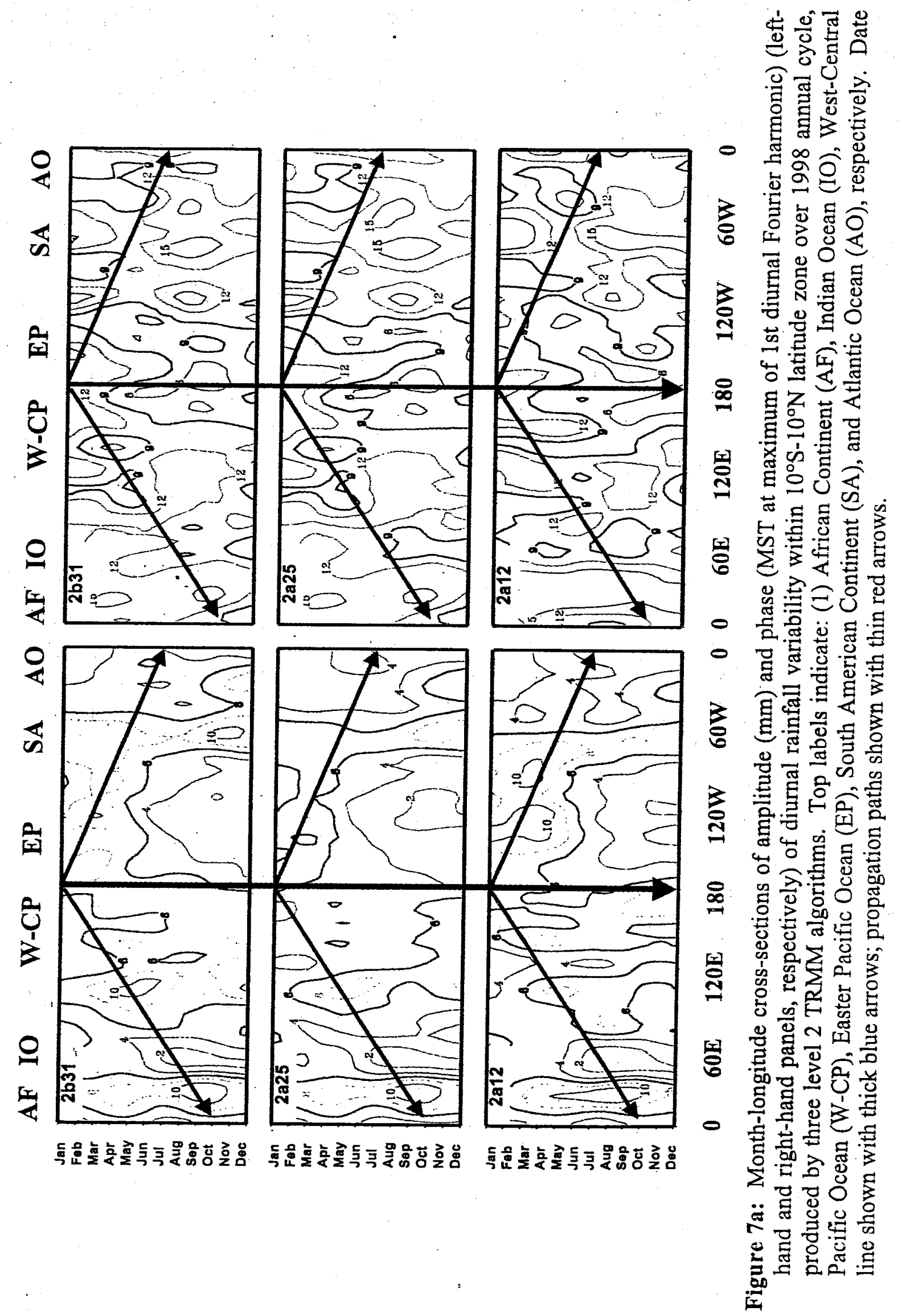




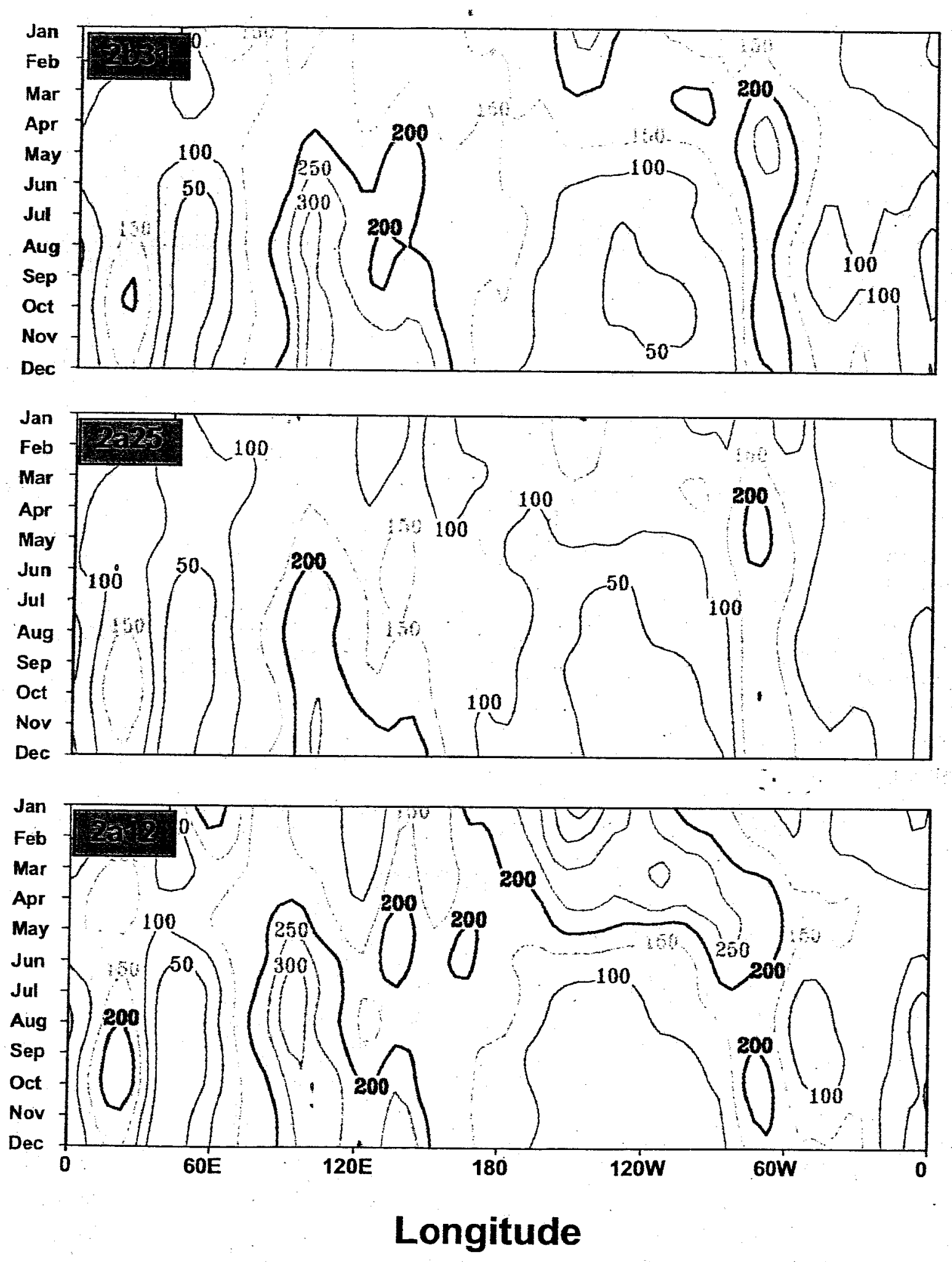

Figure 7b: Rainfall accumulation (mm) associated with Fig. 7a. 

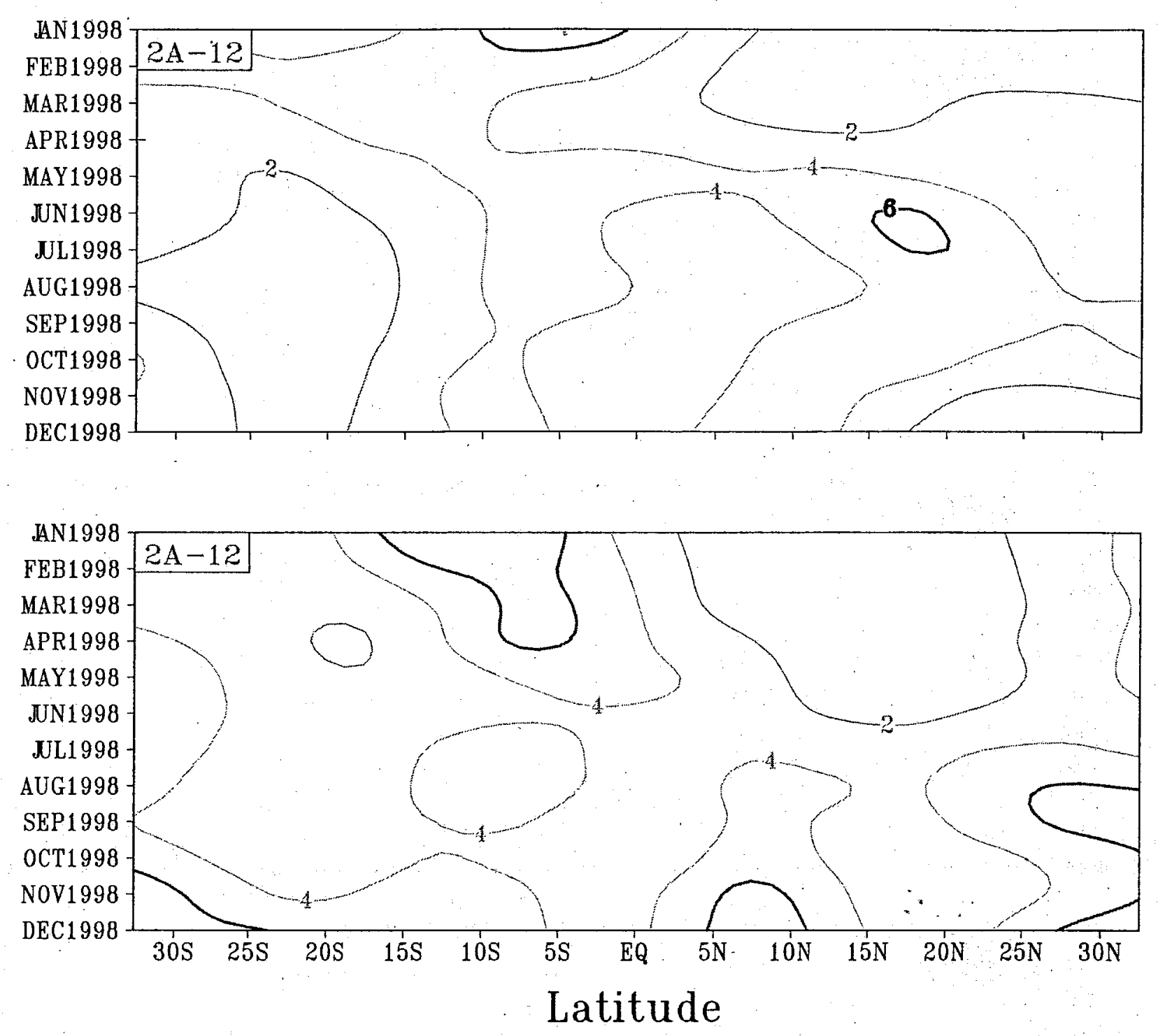

Figure 8a: Month-latitude cross-sections of amplitude $(\mathrm{mm})$ of diurnal rainfall variability for $50^{\circ}-110^{\circ} \mathrm{E}$ (upper panel) and $150^{\circ} \mathrm{E}-150^{\circ} \mathrm{W}$ (lower panel) longitude sectors over 1998 annual cycle produced by 2a12 TRMM algorithm. 

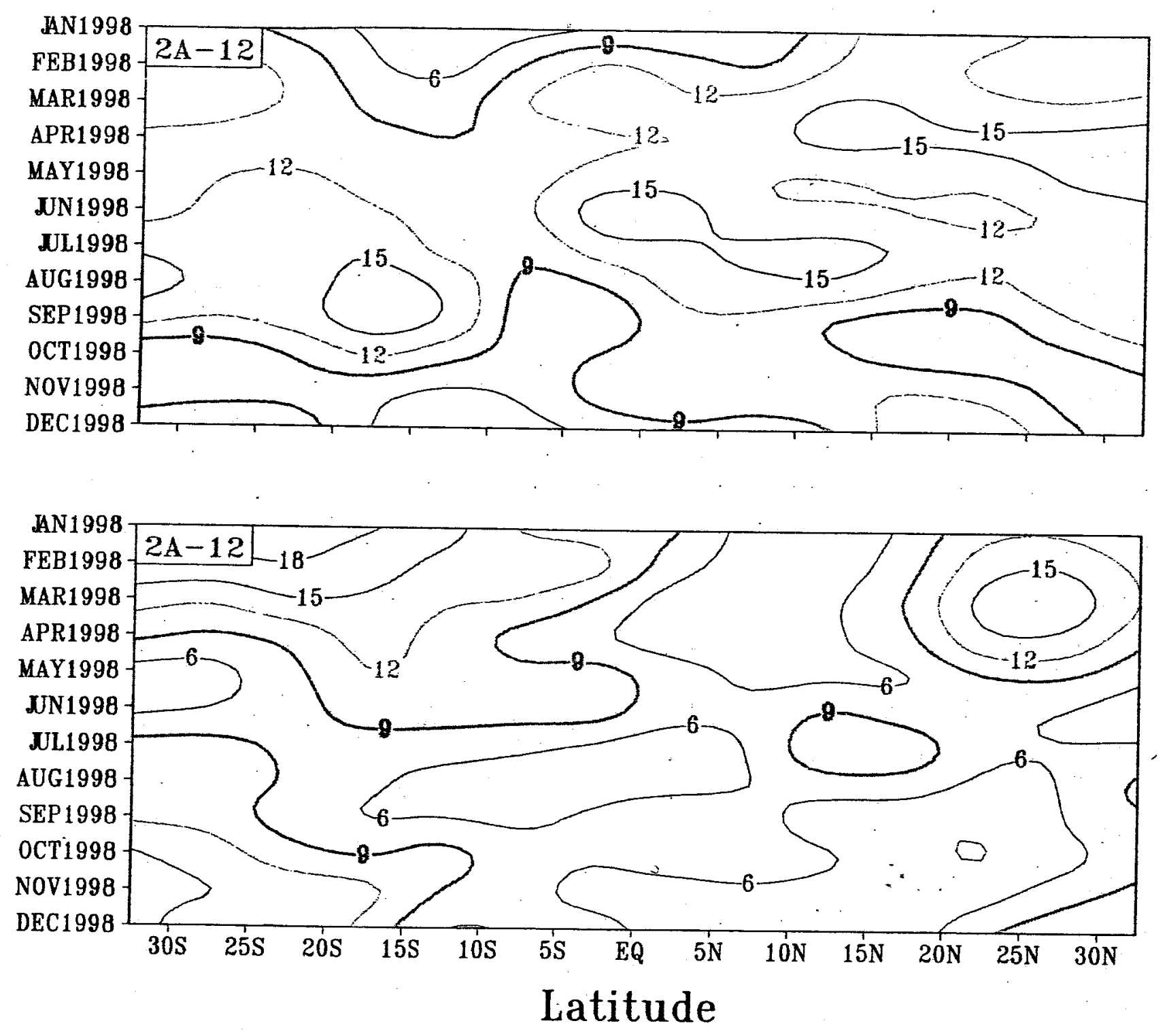

Figure 8b: Same as Fig. 8a, except for phase (MST at maximum of 1st diurnal Fourier harmonic). 


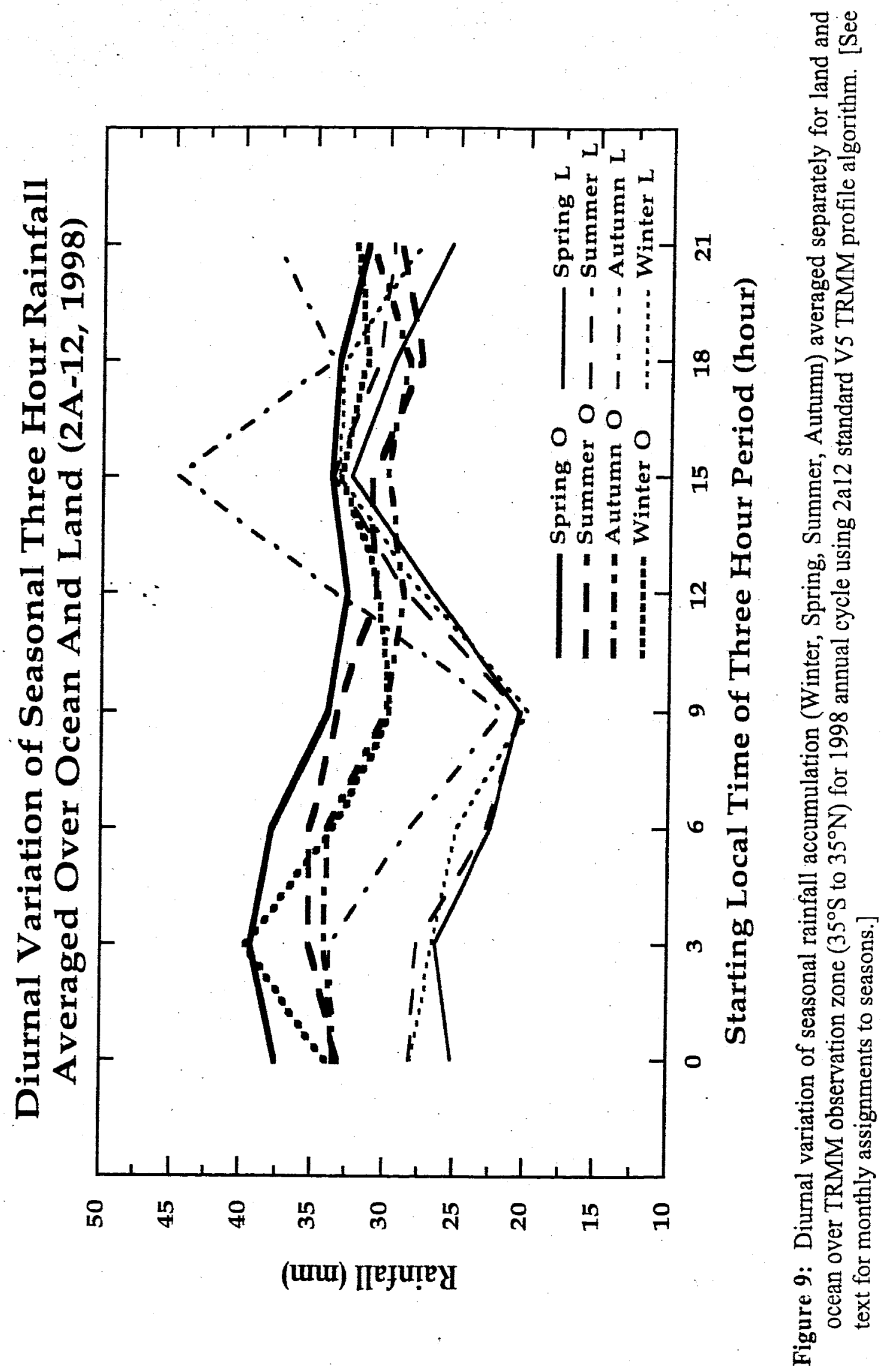

in 


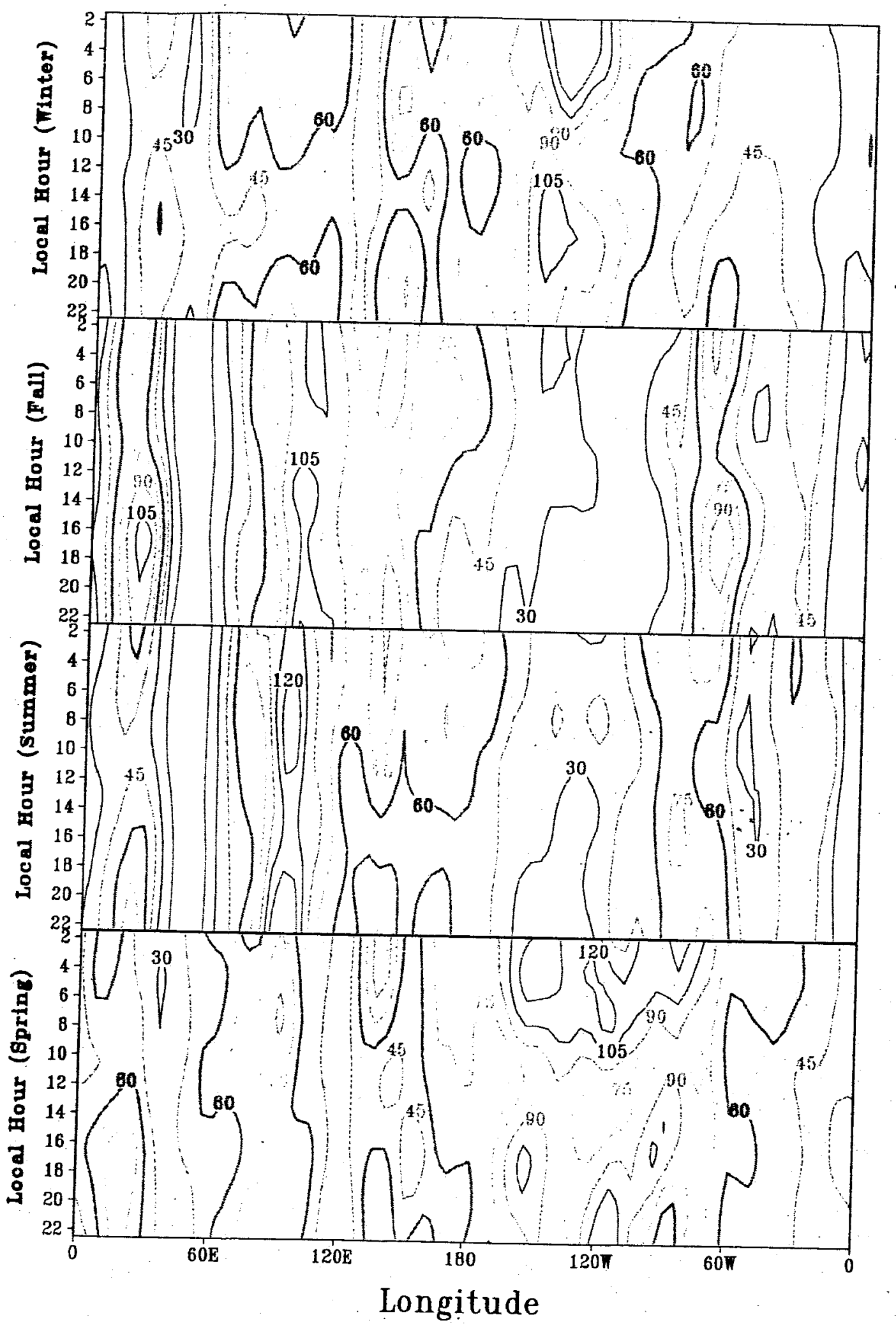

Figure 10: Diurnal-longitude cross-sections for four seasons of rainfall accumulation (mm) for $10^{\circ} \mathrm{S}-10^{\circ} \mathrm{N}$ latitude zone over 1998 annual cycle produced by 2a12 TRMM algorithm. 


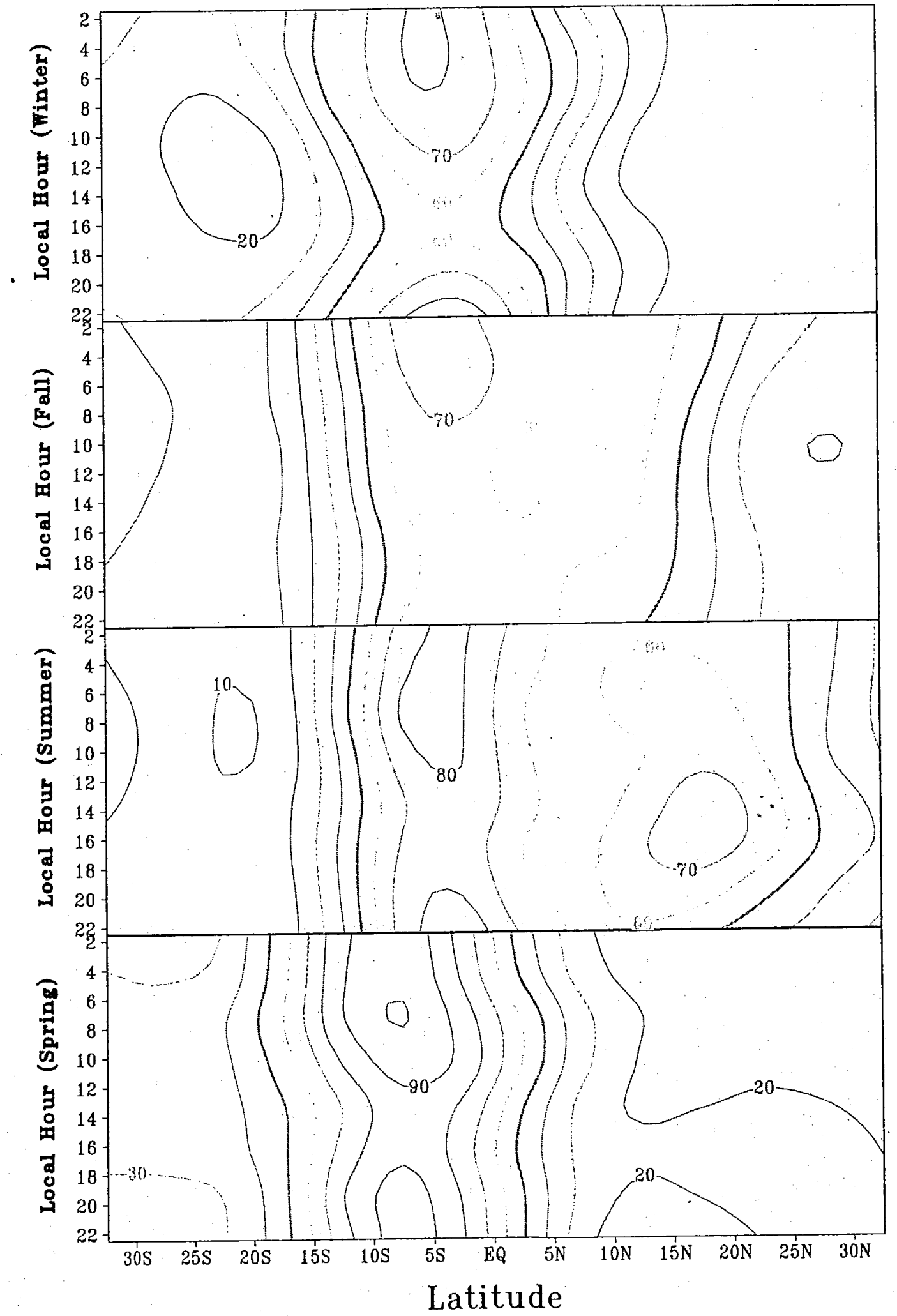

Figure 11a: Diurnal-latitude cross-sections for four seasons of rainfall accumulation (mm) for $50^{\circ}-110^{\circ} \mathrm{E}$ longitude sector over 1998 annual cycle produced by $2 \mathrm{a} 12 \mathrm{TRMM}$ algorithm. 


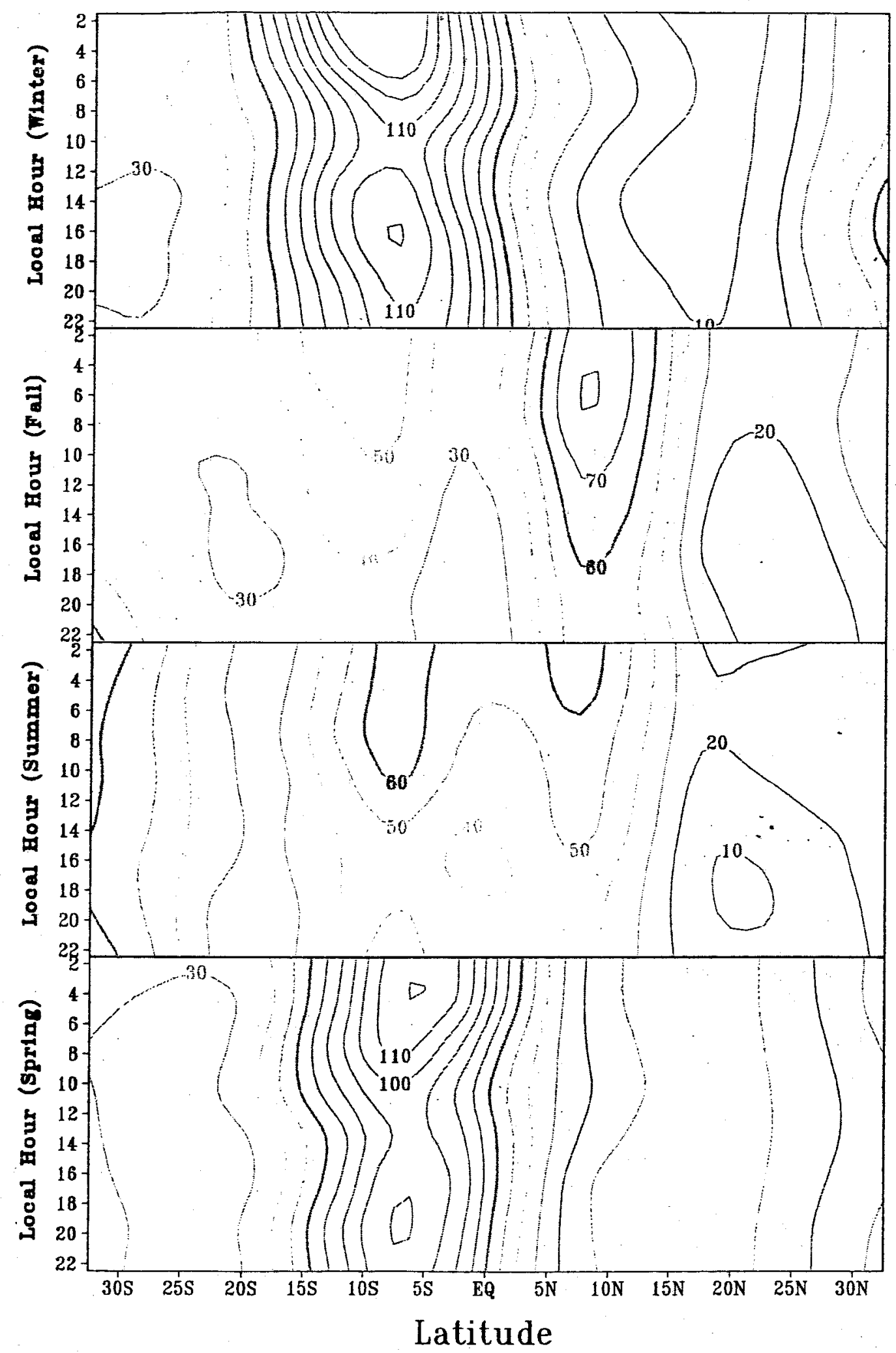

Figure 11b: Same as Fig 11a, except for $150^{\circ} \mathrm{E}-150^{\circ} \mathrm{W}$ longitude sector. 

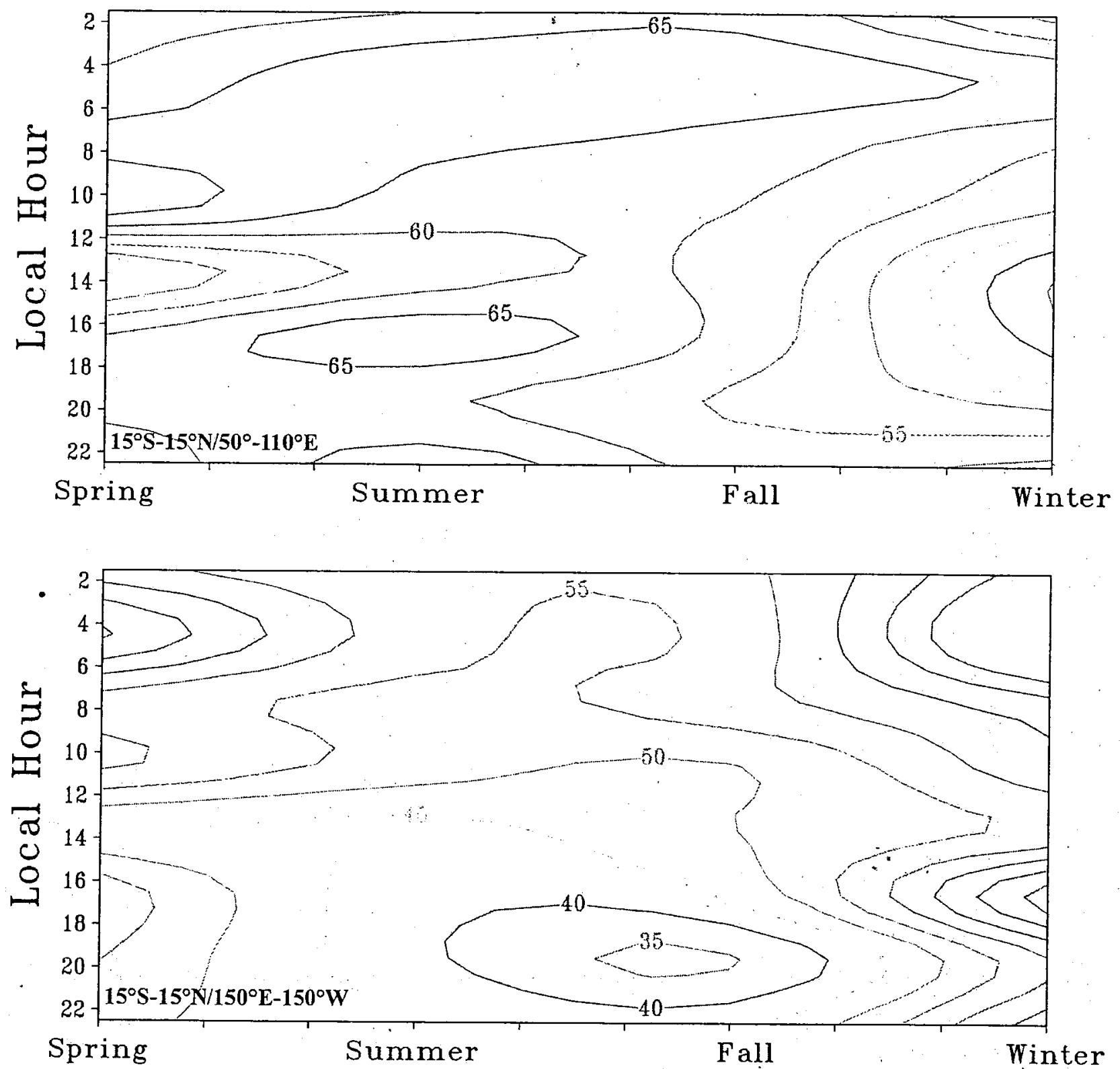

Figure 12: Diurnal-season cross-sections of rainfall accumulation $(\mathrm{mm})$ for region in Indian Ocean $\left(15^{\circ} \mathrm{S}-15^{\circ} \mathrm{N} / 50^{\circ}-110^{\circ} \mathrm{E}\right)$ (upper panel) and region in Pacific ocean $\left(15^{\circ} \mathrm{S}-15^{\circ} \mathrm{N} /\right.$ $150^{\circ} \mathrm{E}-150^{\circ} \mathrm{W}$ ) (lower panel) over 1998 annual cycle produced by 2a12 TRMM algorithm. 


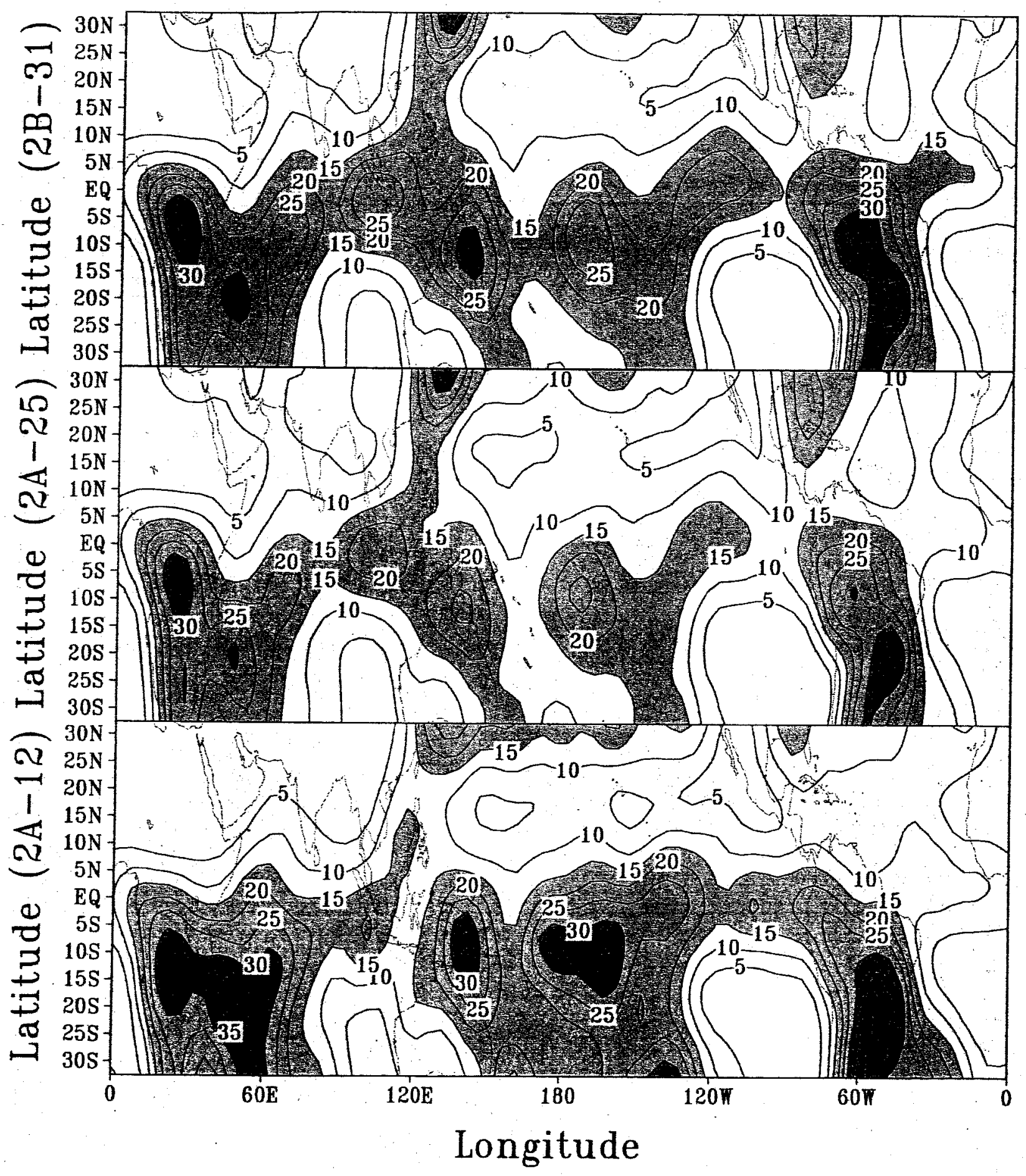

Figure 13a: Distributions of amplitude (mm) of rainfall variability for Winter-1998 produced by $2 \mathrm{~b} 31,2 \mathrm{a} 25$, and 2a12 TRMM algorithms -- with shaded areas indicating amplitudes of 15 , 30 , and $45 \mathrm{~mm}$, respectively. 


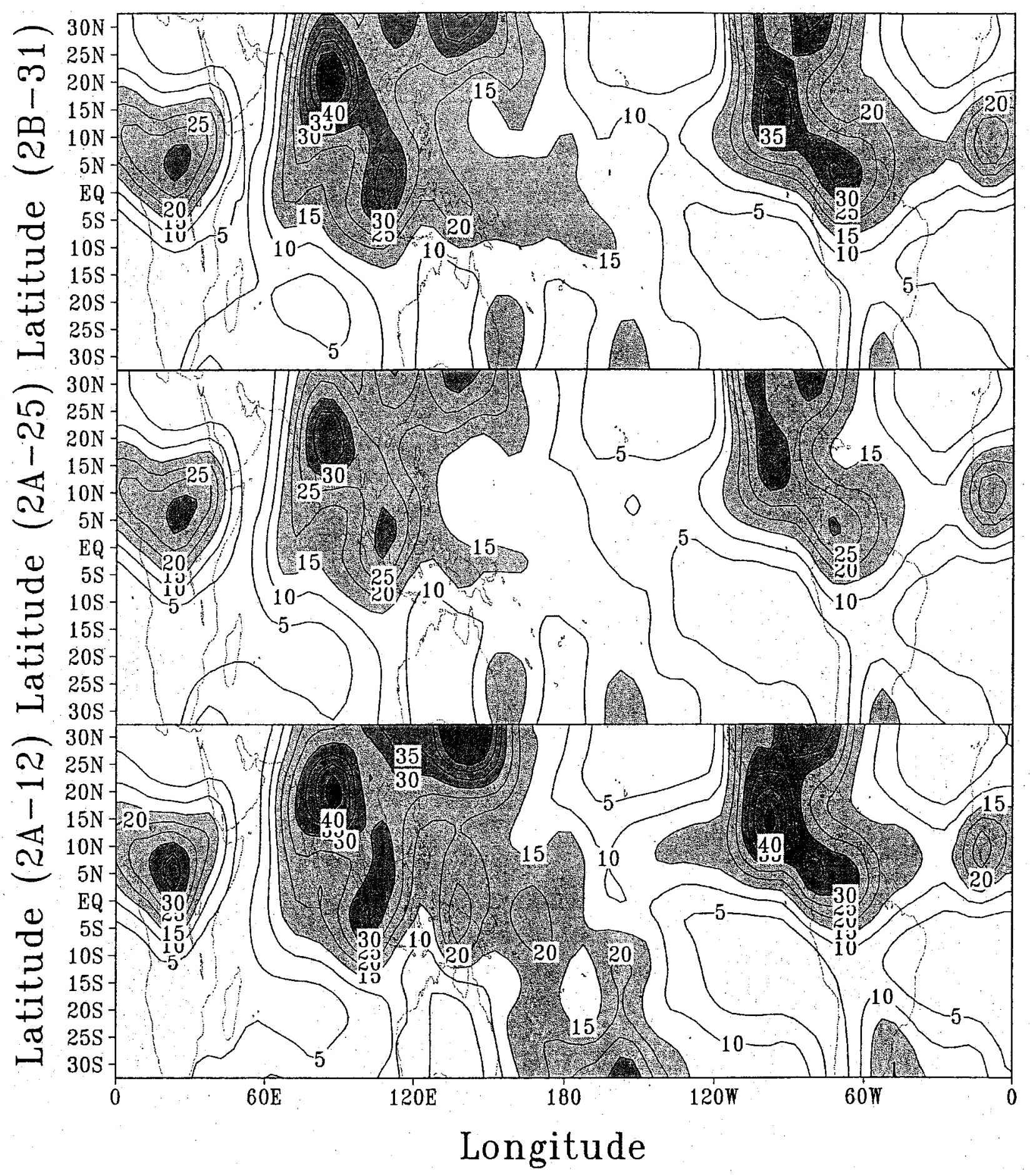

Figure 13b: Same as Fig. 13a, except for Summer-1998 - shaded areas indicate regions of largest amplitude. 


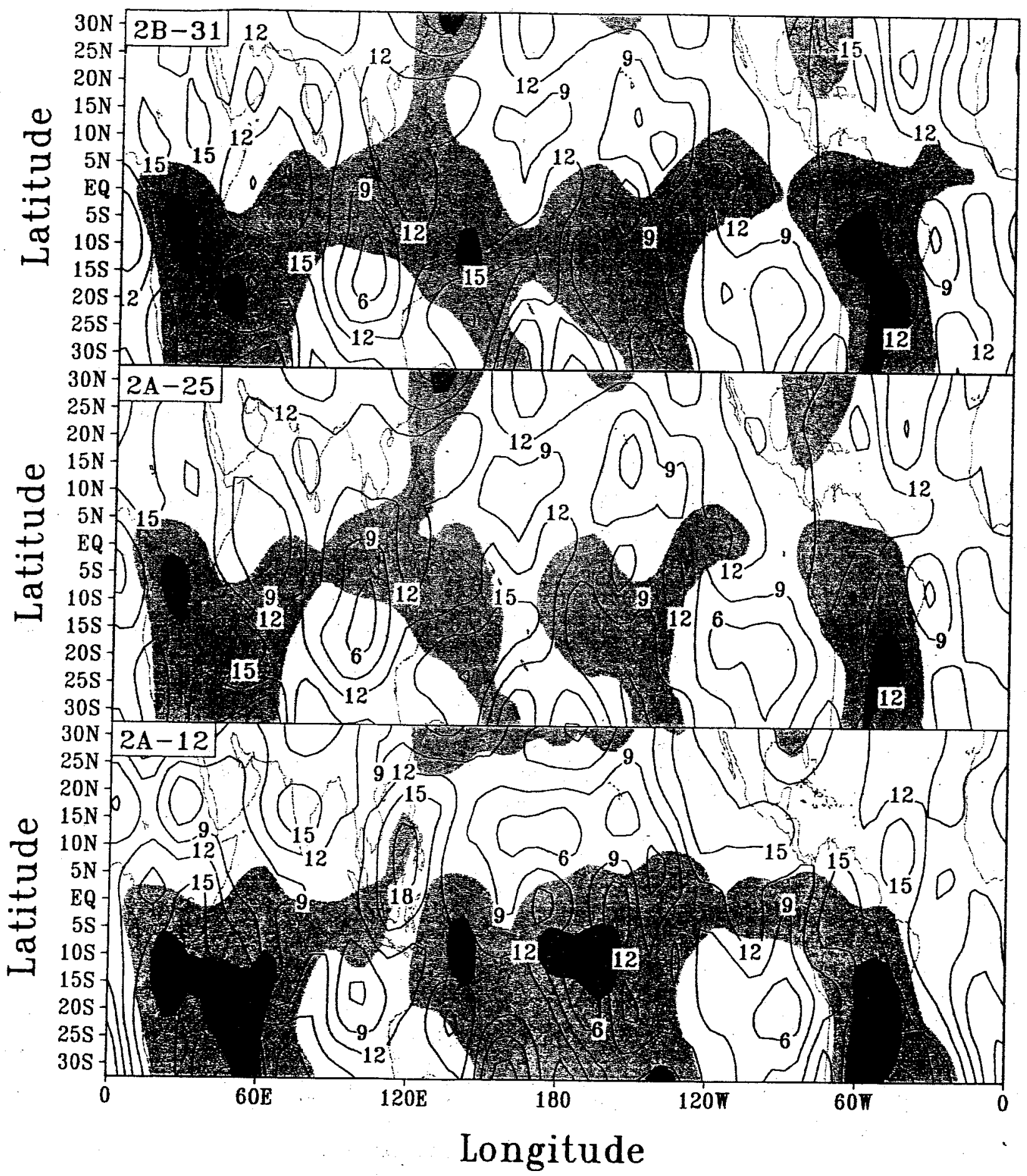

Figure 14a: Distributions of phase (MST at maximum of 1st diurnal Fourier harmonic) of rainfall variability for Winter-1998 produced by $2 \mathrm{~b} 31,2 \mathrm{a} 25$, and 2a12 TRMM algorithms -shaded areas indicate regions of largest amplitudes as shown in Fig. 13a. 


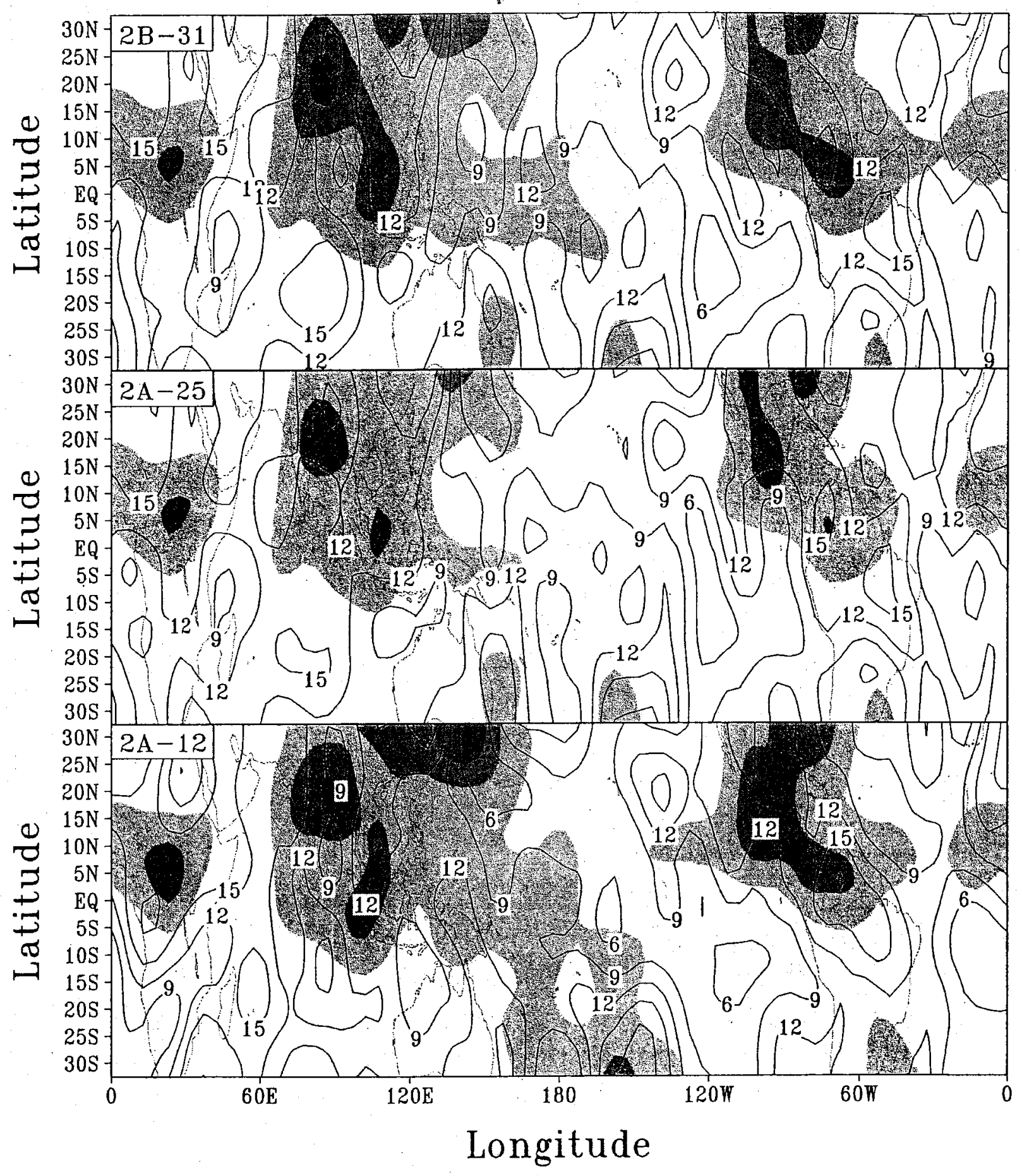

Figure 14b: Same as Fig. 14a, except for Summer-1998 -- shaded areas indicate regions of largest amplitudes. 


\title{
Popular Summary
}

\section{Mechanisms for Diurnal Variability of Global Tropical Rainfall Observed from TRMM}

\author{
Song Yang ${ }^{1}$ and Eric A. Smith ${ }^{2}$ \\ 1 School of Computational Sciences, George Mason Univ., Fairfax, VA 22030 \\ [Mail Code 912.1, NASA/Goddard Space Flight Center, Greenbelt, MD 20771 \\ (301) 286-4961; <ysong@agnes.gsfc.nasa.gov> \\ 2 NASA/Goddard Space Flight Center, GPM Project Science/Code 912.1, Greenbelt, MD 20771 \\ (301) 286-5770; <eric.a.smith@nasa.gov> \\ Submitted to Journal of Climate
}

This paper describes the tropical-subtropical rainfall diurnal variations and their possible causes using the most recent Tropical Rainfall Measuring Mission (TRMM) measurements. The TRMM precipitation was retrieved from the TRMM Microwave Imager (TMI), Precipitation Radar (PR), and TMI/PR Combined algorithms. The features of rainfall diurnal variability for the 1998 annual cycle from above three methods are similar so that TRMM rain products could provide reliable estimates of rainfall variability.

Results show that there are generally more nighttime oceanic rainfall and more daytime continental rainfall. The dominant features of rainfall diurnal cycle are a rainfall maximum in late-evening/early-morning over ocean and a rainfall maximum in the mid-to late-afternoon over land. The oceanic rainfall has a secondary peak in the mid- to late- afternoon, while the continental rainfall has a secondary maximum in the late-evening/early-morning. In addition, rainfall diurnal cycle has a seasonal variability. Amplitude and phase analysis techniques have been used in investigating the rainfall diurnal variability. The amplitude could be considered as the strength of the diurnal cycle while the phase could be used to indicate which hour the rainfall has a maximum. Evidence indicates that there is a good relationship between the rainfall diurnal pattern/its seasonal evolution and the rainfall accumulation pattern/its seasonal evolution. The oceanic rainfall diurnal variability is related to large-scale convections, and is an important part of the atmospheric general circulation. It is not always true for rainfall over land.

Results from published studies have suggested many different causes of the rainfall diurnal behavior. For example, the dynamic radiation-convection interaction theory could explain the oceanic rainfall morning peak, while the land surface heating could be the cause of the maximum afternoon rainfall over land. However, they could not be the causes of the second rainfall maximum in the afternoon over ocean and in the morning over land. Analysis in this study reveals differences in regional and seasonal features of the rainfall diurnal cycle, indicating that causes of rainfall diurnal variations differ from place to place. The TRMM observational evidence is used to support or reject these existing mechanisms. 